\title{
Mechanisms for Tropical Tropospheric Circulation Change in Response to Global Warming*
}

\author{
JIAN MA \\ Department of Meteorology, University of Hawaii at Manoa, Honolulu, Hawaii \\ SHANG-PING XIE \\ Department of Meteorology, and International Pacific Research Center, School of Ocean and Earth Science and Technology, \\ University of Hawaii at Manoa, Honolulu, Hawaii \\ YU KOSAKA \\ International Pacific Research Center, School of Ocean and Earth Science and Technology, \\ University of Hawaii at Manoa, Honolulu, Hawaii
}

(Manuscript received 21 January 2011, in final form 3 August 2011)

\begin{abstract}
The annual-mean tropospheric circulation change in global warming is studied by comparing the response of an atmospheric general circulation model (GCM) to a spatial-uniform sea surface temperature (SST) increase (SUSI) with the response of a coupled ocean-atmosphere GCM to increased greenhouse gas concentrations following the A1B scenario. In both simulations, tropospheric warming follows the moist adiabat in the tropics, and static stability increases globally in response to SST warming. A diagnostic framework is developed based on a linear baroclinic model (LBM) of the atmosphere. The mean advection of stratification change (MASC) by climatological vertical motion, often neglected in interannual variability, is an important thermodynamic term for global warming. Once MASC effect is included, LBM shows skills in reproducing GCM results by prescribing latent heating diagnosed from the GCMs.

MASC acts to slow down the tropical circulation. This is most clear in the SUSI run where the Walker circulation slows down over the Pacific without any change in SST gradient. MASC is used to decelerate the Hadley circulation, but spatial patterns of SST warming play an important role. Specifically, the SST warming is greater in the Northern than Southern Hemisphere, an interhemispheric asymmetry that decelerates the Hadley cell north, but accelerates it south of the equator. The MASC and SST-pattern effects are on the same order of magnitude in our LBM simulations. The former is presumably comparable across GCMs, while SST warming patterns show variations among models in both shape and magnitude. Uncertainties in SST patterns account for intermodel variability in Hadley circulation response to global warming (especially on and south of the equator).
\end{abstract}

\section{Introduction}

Large-scale atmospheric circulation is important for moisture and energy transport, precipitation, tropical

\footnotetext{
* International Pacific Research Center Publication Number 830 and School of Ocean and Earth Science and Technology Publication Number 8519.

Corresponding author address: Jian Ma, Department of Meteorology, SOEST, University of Hawaii at Manoa, Honolulu, HI 96822.

E-mail: jianma@hawaii.edu
}

cyclone (TC) development, and ocean-land-atmosphere interactions. In the tropics, where the synoptic eddy effects are weak, tropospheric circulation is primarily generated by the uneven distribution of diabatic heating/cooling (e.g., convective latent heating in convergence zones). Climatologically, these forcing terms are nearly in balance with vertical advection (e.g., Rodwell and Hoskins 1996). In global warming, vertical advection and diabatic forcing would change, and large-scale circulation has to alter accordingly to regain the thermodynamic balance.

Reduction of tropical convective mass flux (Held and Soden 2006) and weakening of the Walker circulation 
(Vecchi et al. 2006; Vecchi and Soden 2007a) are found in the World Climate Research Programme's (WCRP's) Coupled Model Intercomparison Project phase 3 (CMIP3) multimodel dataset. Two complementary thermodynamic constraints were proposed to explain the weakening of the tropical circulation. One argument is based on the faster increase in dry static stability than in subtropical radiative cooling (Knutson and Manabe 1995), and the other on the slower increase of global-mean precipitation than atmospheric specific humidity (Held and Soden 2006), though satellite-based microwave measurements question this model result on change of the hydrological cycle (Wentz et al. 2007). Neither constraint explains why the Walker cell is preferably weakened rather than the Hadley cell. Observations ( $\mathrm{Hu}$ and $\mathrm{Fu} 2007)$ and general circulation model (GCM) simulations (Lu et al. 2007; Frierson et al. 2007; Johanson and $\mathrm{Fu} 2009$ ) show a robust poleward expansion of the Hadley circulation. The intensity change of the Hadley circulation, however, is not as robust as that of the Walker cell (Vecchi and Soden 2007a). The difference in these two circulation responses has not been thoroughly examined in the literature.

Currently, two paradigms exist for explaining tropical rainfall change in global warming. One implicitly assumes a spatially uniform sea surface temperature (SST) increase (SUSI) and predicts rainfall to increase in the core of existing rainy regions ("wet get wetter"), and to decrease on their margins (called "upped ante") and in current dry areas, based on an argument of intensified moisture advection due to atmospheric warming (Chou and Neelin 2004; Chou et al. 2009). The destabilizing effects of increased low-level moisture were once suggested to enhance tropical convection (Lindzen 1990), but not supported by simulations with one-dimensional radiative convective models (Betts and Ridgway 1989; Betts 1998) and GCMs (Knutson and Manabe 1995; Held and Soden 2006).

The other paradigm for rainfall change emphasizes the effects of tropical SST patterns on convective reorganization, as are apparent in instrumental observations, in particular in El Niño-Southern Oscillation (ENSO; Alexander et al. 2002). Deviations of SST warming from its tropical mean are suggested to play the leading role for changes in TC activity (Vecchi and Soden 2007b; Vecchi et al. 2008; Knutson et al. 2008), precipitation (Xie et al. 2010; Johnson and Xie 2010), and the Hadley circulation (Gastineau et al. 2009). This "warmer-get-wetter" view is based on the argument that the upper-tropospheric warming is nearly spatially uniform in the tropics because of fast waves, so convective instability is largely determined by spatial variations in SST warming (Vecchi and Soden 2007b; Xie et al. 2010; Johnson and Xie 2010).
The SST warming in CMIP3 simulations features an equatorial peak (Liu et al. 2005; Xie et al. 2010), which is often characterized as El Niño-like. However, the zonal mean tropospheric warming patterns, changes in zonal wind shear, and Hadley cell are all quite different from El Niño (Lu et al. 2008). This appears to be due to the difference in the tropical mean SST warming relative to the spatial patterns between El Niño and global warming. In a 10-member ensemble simulation with the National Oceanic and Atmospheric Administration (NOAA) Geophysical Fluid Dynamics Laboratory (GFDL) Climate Model, version 2.1 (CM2.1) for 1996-2050 under the Special Report on Emissions Scenarios (SRES) A1B (Xie et al. 2010), the tropical $\left(20^{\circ} \mathrm{S}-20^{\circ} \mathrm{N}\right)$ mean SST warming is $1.12 \mathrm{~K}$ with a spatial standard deviation of $0.21 \mathrm{~K}$ (19\% of the tropical mean). By contrast, El Niño events in the same model feature an SST standard deviation of $0.76 \mathrm{~K}, 140 \%$ of the tropical mean warming of $0.55 \mathrm{~K}$ (not shown). Thus, ENSO is dominated by SST patterns, while global warming is dominated by the tropical mean.

Figure 1 illustrates the relative importance of tropical mean SST warming versus its patterns for tropospheric circulation change by comparing the annual mean results of the GFDL CM2.1 A1B simulation with its Atmospheric Model, version 2.1 (AM2.1) forced by a SUSI of $2 \mathrm{~K}$. Tropospheric warming patterns, defined as deviations from the tropical mean, are similar between two runs, with a spatial correlation coefficient $(r)$ of 0.59 (Table 1). Both cases feature maxima in the subtropics and a minimum in the Indo-Pacific warm pool that extends to the intertropical convergence zone (ITCZ) and the South Pacific convergence zone (SPCZ). Fu et al. (2006) showed the enhanced subtropical warming from satellite observations and suggested that it pushes the tropospheric jet streams poleward, contributing to the Hadley cell expansion. The zonal mean warming patterns (Fig. 2) are very similar between SUSI and A1B ( $r=$ 0.91), both featuring an elevated maximum warming at $300 \mathrm{hPa}$, a result of moist adiabatic adjustment (Knutson and Manabe 1995). In thermal-wind balance with temperature, the $300-850-\mathrm{hPa}$ wind shear decreases with anomalous easterly shear in the tropical Pacific (Fig. 1). The shear response is similar between SUSI and A1B ( $r=0.57$ for zonal wind shear).

Apparent differences from the SUSI run include the development of meridional asymmetry in the A1B run over the eastern tropical Pacific (Figs. $1 \mathrm{~b}$ and $2 \mathrm{~b}$ ), with southerly cross-equatorial wind shear. Besides, wind shear changes in the tropical Indian Ocean are opposite between the two runs. These differences are primarily induced by SST patterns.

Linear baroclinic models (LBMs) of Matsuno (1966) and Gill (1980) forced with SST-induced diabatic 


\section{(a) SUSI}

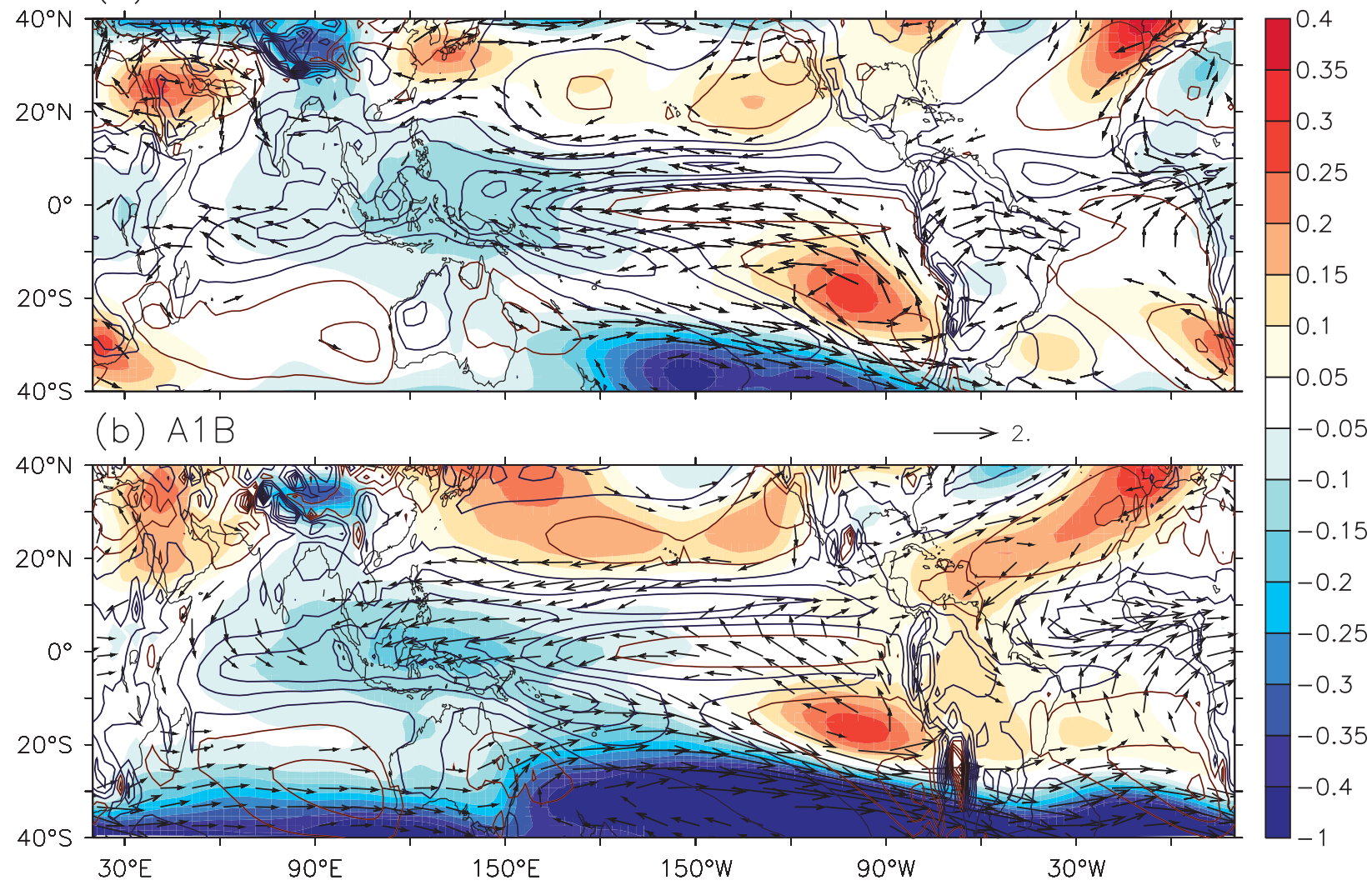

FIG. 1. Annual mean 300-850-hPa-averaged climatological mean pressure velocity [contour interval (CI) $0.02 \mathrm{~Pa} \mathrm{~s}{ }^{-1}$; 0 omitted], air temperature warming deviations (color shading, $\mathrm{K})$ from the tropical $\left(40^{\circ} \mathrm{S}-40^{\circ} \mathrm{N}\right)$ mean, and $300-850$-hPa wind shear change $($ vectors, $\mathrm{m} \mathrm{s}^{-1}$ ) simulated with GFDL AM2.1-CM2.1 under (a) SUSI and (b) SRES A1B scenarios, respectively.

heating are very useful to simulate and understand the mean state and variability of tropical circulation. The SUSI results illustrate that in the absence of gradients in SST forcing, considerable changes in atmospheric circulation are excited by global warming, and they are similar to those in the A1B simulation by a coupled model. Thus, something is missing in LBMs and adjustments are necessary for such models to become a useful diagnostic tool for global warming research.

This study investigates mechanisms for tropical circulation change in response to global warming. Specific questions we seek to address include the following: Why does the troposphere warm less over convective than subsidence regions? To what extent do patterns of SST change affect patterns of tropospheric warming and circulation change? What determines the change in tropical overturning circulations and its uncertainty? We design a diagnostic framework to identify robust dynamical balance and simulate major features of the circulation change with an LBM. Watanabe and Kimoto (2000) originally developed the LBM, and we modify it for global warming studies. We show that it is important to include the effect of increased static stability. With this modification, the LBM is skillful in reproducing salient features of circulation change in both GCM runs under the SUSI and A1B forcing. The LBM proves to be useful in quantifying SST pattern effects.

The rest of the paper is organized as follows. Section 2 describes the data and models. Section 3 introduces the diagnostic framework utilizing the LBM, describes the forcing factors, and presents the experimental designs. Section 4 reports results from the LBM simulations and explores effects of various forcing factors. Section 5

TABLE 1. Annual mean spatial correlation coefficient $\left(r, 40^{\circ} \mathrm{S}-\right.$ $40^{\circ} \mathrm{N}$ ) of various variables in GFDL CM2.1 simulation under SUSI and $\mathrm{A} 1 \mathrm{~B}$ scenarios. The $T^{*}$ is the atmospheric warming patterns, $U^{\prime}$ is the change of zonal wind, and $\omega$ is the climatological pressure velocity. Subscripts va denotes vertical $(300-850 \mathrm{hPa})$ average, $\mathrm{zm}$ for zonal mean, and sh for 300-850-hPa wind shear.

\begin{tabular}{ccccc}
\hline \hline & $\begin{array}{c}\left.T_{\text {va }}^{*}\right|_{\text {SUSI }}, \\
\left.T_{\text {va }}^{*}\right|_{\text {A1B }}\end{array}$ & $\begin{array}{c}\left.U_{\text {sh }}^{\prime}\right|_{\text {SUSI }}, \\
\left.U_{\text {sh }}^{\prime}\right|_{\text {A1B }}\end{array}$ & $\begin{array}{c}\left.T_{\text {zm }}^{*}\right|_{\text {SUSI }}, \\
\left.T_{\text {zm }}^{*}\right|_{\text {A1B }}\end{array}$ & $\begin{array}{c}\omega_{\text {va }}, \\
\left.T_{\text {val }}^{*}\right|_{\text {SUSI }}\end{array}$ \\
\hline$r$ & 0.59 & 0.57 & 0.91 & 0.38 \\
\hline
\end{tabular}




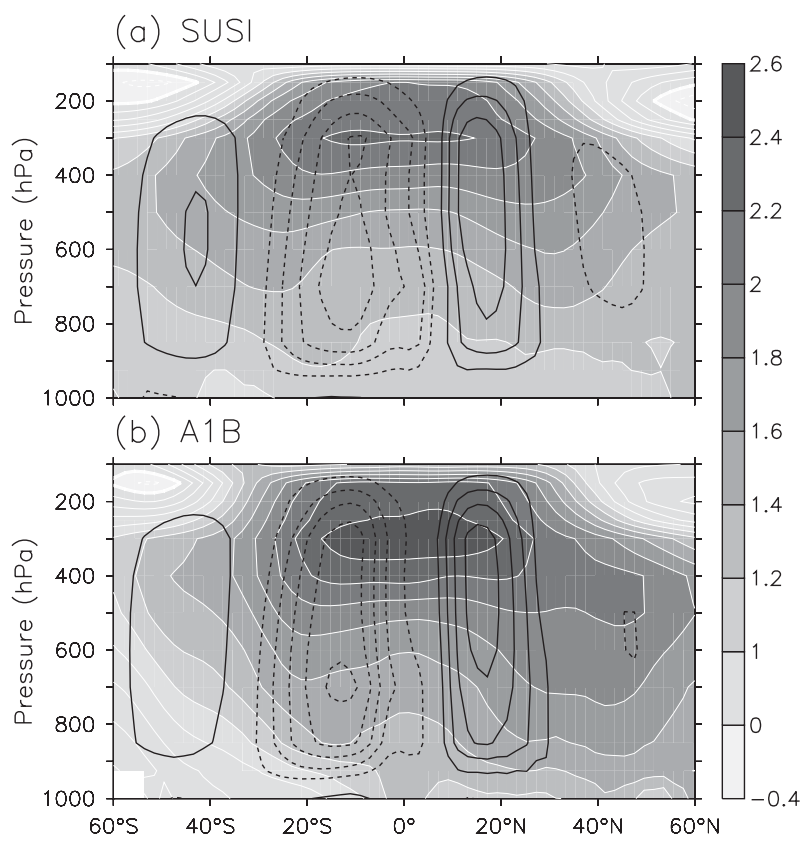

FIG. 2. Latitude-height section of annual and zonal mean tropospheric air temperature change (gray shading, K) and climatological meridional streamfunction (black contours, CI: $2 \times$ $10^{10} \mathrm{~kg} \mathrm{~s}^{-1} ; 0$ omitted) simulated with GFDL AM2.1/CM2.1 under (a) SUSI and (b) SRES A1B scenarios, respectively.

focuses on the overturning circulations and section 6 presents the conclusions with a discussion.

\section{Data and models}

\section{a. GCMs}

We diagnose the forcing terms from global warming simulations by NOAA GFDL models under SUSI and A1B scenarios. The CM2.1 uses the Flexible Modeling System to couple the GFDL AM2.1 with the Modular Ocean Model version 4. The AM2.1 builds on a finitevolume atmospheric dynamical core and includes atmospheric physical packages and a land surface model. Its resolution is $2^{\circ}$ latitude $\times 2.5^{\circ}$ longitude with 24 vertical levels, 9 of which are located in the lowest $1.5 \mathrm{~km}$ to represent the planetary boundary layer. The ocean model uses a finite-difference approach to solve the primitive equations. The resolution is $1^{\circ}$ longitude by $1^{\circ}$ latitude, with meridional grid spacing decreasing to $1 / 3^{\circ}$ toward the equator. The model has 50 vertical levels, 22 of which are in the upper $220 \mathrm{~m}$. A detailed description of CM2.1 can be found in GFDL Global Atmospheric Model Development Team (2004) and Delworth et al. (2006). Long integrations ( $2000 \mathrm{yr})$ have been performed under current climate forcing without flux correction, reaching statistically steady states similar to observations, including the annual-mean state, seasonal cycle, and major modes of interannual variability (Wittenberg et al. 2006).

The SUSI experiment was performed with AM2.1 for the period of 1983-91, by adding a uniform SST increase of $2 \mathrm{~K}$. Another set of doubling $\mathrm{CO}_{2}$ experiments by AM2.1 during 1981-2000 is also used to isolate the atmospheric response to radiative forcing (noted as RAD). Both of the SUSI and RAD experiments employ interannualvariable monthly mean observed SST.

The SRES A1B scenario for the emission of climatically important trace gases (e.g., carbon dioxide and ozone) is based on certain socioeconomic development paths for the twenty-first century. It roughly projects a doubling of atmospheric $\mathrm{CO}_{2}$ in 2100 from the preindustrial level, with a recovery of the Southern Hemisphere "ozone hole" approximately by 2050 . For this scenario, a 10-member ensemble simulation has been completed at GFDL with CM2.1 from 1996 to 2050, during which $\mathrm{CO}_{2}$ concentration increases from 369 to $532 \mathrm{ppm}$. We analyze ensemble-mean, 50-yr difference fields: 2046-50 minus 1996-2000. The use of ensemble means helps reduce natural variability and isolate the response to the greenhouse gas (GHG) increase. The annual-mean SST rise averaged in the tropics $\left(20^{\circ} \mathrm{S}-20^{\circ} \mathrm{N}\right)$ is $1.12 \mathrm{~K}$ in $\mathrm{CM} 2.1$.

To explore the differences among models, in particular those in the Hadley circulation change influenced by SST patterns, we perform intermodel singular value decomposition (SVD) analyses with 23 CMIP3 GCMs under the A1B scenario, except the Meteorological Institute of the University of Bonn, ECHO-G Model (MIUB ECHOG) for which tropospheric wind data are unavailable. (Details of the models can be found at http:// www-pcmdi.llnl.gov/ipcc/model_documentation/ipcc_ model_documentation.php, and the output at https:// esg.llnl.gov:8443/index.jsp.) Only one realization is used for each model (including the GFDL CM2.1). Because internal variability could be strong in each realization, changes are computed for the twenty-first century between two 10-yr periods: 2001-10 and 2091-2100, to extract robust anthropogenic global warming signals.

All changes in this study are normalized by the tropical mean SST warming $\left(20^{\circ} \mathrm{S}-20^{\circ} \mathrm{N}\right)$ in each model before the computation of ensemble means or SVD analyses, except for the RAD run whose results are scaled by $\delta_{\mathrm{InCO}_{2} \mid 2100} / \delta_{\mathrm{InCO}_{2} \mid 2050}=1.91$, since $\mathrm{CO}_{2}$ radiative forcing is proportional to the logarithm of its concentration, and then by the tropical mean SST warming of CM A1B $(1.12 \mathrm{~K})$.

\section{b. $L B M$}

This study adopts an LBM to study mechanisms for circulation change. It is the dry version of a global, 
time-dependent, primitive equation atmospheric model based on a set of linearized equations for vorticity, divergence, temperature, and the logarithm of surface pressure (Watanabe and Kimoto 2000; Watanabe and Jin 2004). The model variables are expressed horizontally in the spherical harmonics at T42 while finite difference is used for the vertical discretization with $20 \sigma$ levels. The model includes biharmonic horizontal diffusion with an $e$-folding time of $3 \mathrm{~h}$ for the highest wavenumber. It also employs Rayleigh friction and Newtonian cooling, whose $e$-folding time scales are set to be 20 days in most of the free troposphere, but 0.5 and 1 day for the 3 lowest $(\sigma>0.9)$ and 2 uppermost $(\sigma<$ $0.03)$ levels, respectively.

LBM is widely used to study atmospheric variability, but its utility for global warming research has not been investigated. We adapt the LBM for the latter purpose by a reformulation that accounts for the effect of global increase in static stability (Fig. 2).

\section{Diagnostic framework with LBM}

\section{a. LBM for global warming studies}

LBM is a powerful tool to relate circulation change to the geographical distribution of diabatic heating. In this section, we develop a diagnostic framework that employs the LBM with necessary modifications, to identify robust dynamical balance and simulate major features of circulation change. An equation for global warming pattern formation is derived from the approximate thermodynamic equation of the atmospheric temperature change:

$$
\left\{\begin{array}{l}
\frac{\partial T^{\prime}}{\partial t}+B \omega^{\prime} \frac{\partial \bar{\theta}}{\partial p}+B \bar{\omega} \frac{\partial \theta^{\prime}}{\partial p}=\mathrm{LH}+\mathrm{SH}+Q_{R} \\
Q_{R}=\mathrm{SW}+\mathrm{LW}_{C}+\mathrm{LW}_{F}-\mathrm{LW}_{R}\left(T^{\prime}\right)
\end{array},\right.
$$

where the overbar and prime denote the mean and change terms, respectively. Here $T$ is air temperature, $\theta$ is potential temperature, $p$ is pressure, $B=T / \theta=$ $\left(p / p_{S}\right)^{R / c_{p}}$, where $p_{S}$ is surface pressure, $R$ is the gas constant for air, and $c_{p}$ is the specific heat at constant pressure. As we are interested in changes in time mean fields, $\partial T^{\prime} / \partial t$ may be omitted. The diabatic forcing includes latent heating $(\mathrm{LH})$, sensible heating $(\mathrm{SH})$ from vertical diffusion, and radiation $\left(Q_{R}\right)$. The $Q_{R}$ is composed of forcing in short wave (SW), long wave (LW) from cloud $\left(\mathrm{LW}_{C}\right)$ and clear-sky GHG $\left(\mathrm{LW}_{F}\right)$, and feedback $\left[\mathrm{LW}_{R}\left(T^{\prime}\right)\right] . \mathrm{LW}_{R}\left(T^{\prime}\right)$ is largely due to clearsky LW change in direct response to atmospheric warming, and is parameterized as the Newtonian damping $\left(\varepsilon T^{\prime}\right)$ in the LBM.
We denote the global average as $\langle x\rangle$, the spatial patterns as $\bar{x}^{*}=\bar{x}-\langle\bar{x}\rangle$ and $x^{*}=x^{\prime}-\left\langle x^{\prime}\right\rangle$ for the mean and change fields, respectively. After the global average, Eq. (1) becomes

$$
B\left\langle\omega^{\prime} \frac{\partial \bar{\theta}}{\partial p}\right\rangle+B\left\langle\bar{\omega} \frac{\partial \theta^{\prime}}{\partial p}\right\rangle=\langle\mathrm{LH}\rangle+\langle\mathrm{SH}\rangle+\left\langle Q_{R}\right\rangle .
$$

Because of the global mass conservation, that is, $\langle\bar{\omega}\rangle=0$ and $\left\langle\omega^{\prime}\right\rangle=0$,

$$
\left\langle\omega^{\prime} \frac{\partial \bar{\theta}}{\partial p}\right\rangle=\left\langle\omega^{\prime} \frac{\partial \bar{\theta}^{*}}{\partial p}\right\rangle, \text { and }\left\langle\bar{\omega} \frac{\partial \theta^{\prime}}{\partial p}\right\rangle=\left\langle\bar{\omega} \frac{\partial \theta^{*}}{\partial p}\right\rangle .
$$

Hence,

$$
B\left\langle\omega^{\prime \prime} \frac{\partial \bar{\theta}^{*}}{\partial p}\right\rangle+B\left\langle\bar{\omega} \frac{\partial \theta^{*}}{\partial p}\right\rangle=\langle\mathrm{LH}\rangle+\langle\mathrm{SH}\rangle+\left\langle Q_{R}\right\rangle,
$$

where the last two terms on the left-hand side represent the contributions of spatial patterns to the global-mean change.

By subtracting Eq. (2) from Eq. (1), one can derive the equation for pattern formation:

$$
\begin{aligned}
& B\left(\omega^{\prime} \frac{\partial \bar{\theta}}{\partial p}-\left\langle\omega^{\prime} \frac{\partial \bar{\theta}^{*}}{\partial p}\right\rangle\right)+B \bar{\omega} \frac{\partial \theta^{*}}{\partial p}+B\left(\bar{\omega} \frac{\partial\left\langle\theta^{\prime}\right\rangle}{\partial p}-\left\langle\bar{\omega} \frac{\partial \theta^{*}}{\partial p}\right\rangle\right) \\
& =\mathrm{LH}^{*}+\mathrm{SH}^{*}+Q_{R}^{*} .
\end{aligned}
$$

Consistent with the "weak temperature gradient" approximation (Bretherton and Sobel 2003), the horizontal variations of potential temperature are much less than the tropical mean (Fig. 2): $\partial \bar{\theta}^{*} / \partial p \ll \partial \bar{\theta} / \partial p$ and $\partial \theta^{*} / \partial p \ll$ $\partial\left\langle\theta^{\prime}\right\rangle / \partial p$. Therefore, one can simplify the above equation into

$$
B \bar{\omega} \frac{\partial \theta^{*}}{\partial p}+B \omega^{\prime} \frac{\partial \bar{\theta}}{\partial p}=-B \bar{\omega} \frac{\partial\left\langle\theta^{\prime}\right\rangle}{\partial p}+\mathrm{LH}^{*}+\mathrm{SH}^{*}+Q_{R}^{*}
$$

Equation (3) forms a diagnostic framework that solves the regional response to imposed heating patterns in global warming. This framework defines terms solvable with the LBM as the response and places them on the left-hand side. They include the warming patterns $\left(\theta^{*}\right)$ and circulation change (vertical motion, $\left.\omega^{\prime}\right)$. The imposed forcing terms are arranged on the right-hand side.

Our major modification of the LBM is to treat $-B \bar{\omega}\left(\partial\left\langle\theta^{\prime}\right\rangle / \partial p\right)$ as a forcing term. As an effect of the global-mean warming on pattern formation, it represents the mean advection of stratification change (MASC). It is part of atmospheric response in full GCMs. The MASC 
SUSI

(a) MASC (color shading), LH* (contour)

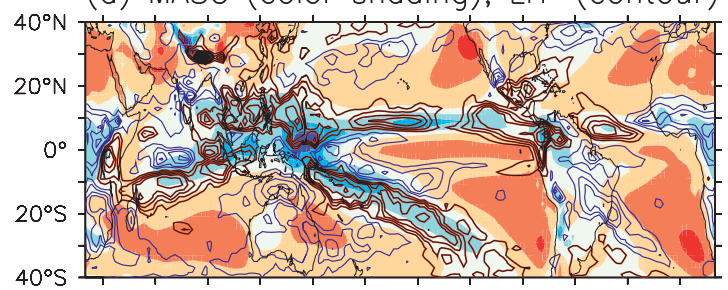

(c) $T^{*}$ (color shading), CC (contour)

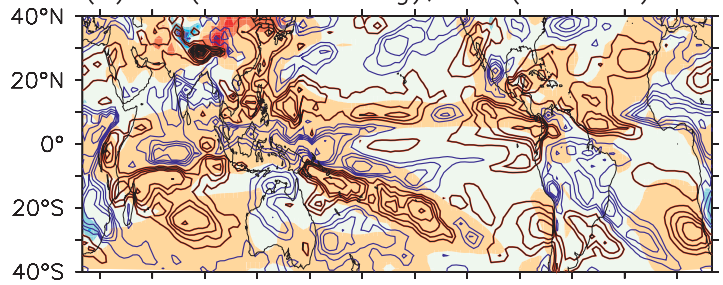

(e) $\mathrm{Q}_{\mathrm{R}}{ }^{*}$ (color shading), $\mathrm{SH}^{*}$ (contour)

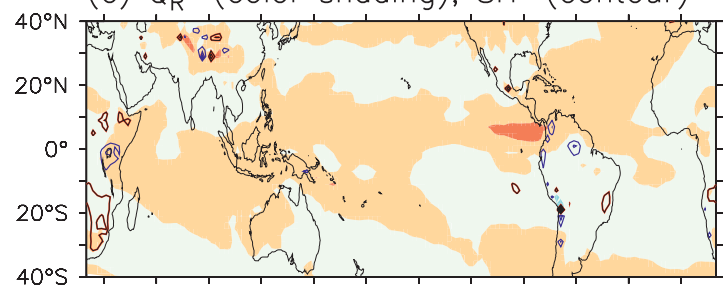

(g) Equatorial mean

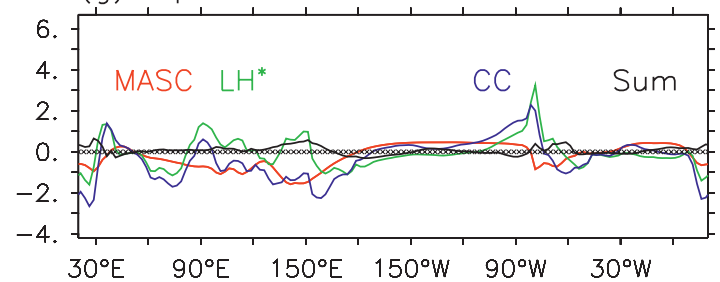

A1B

(b) MASC (color shading), LH* (contour)

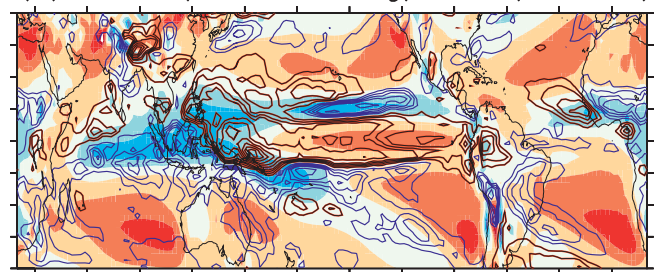

(d) $T^{*}$ (color shading), CC (contour)

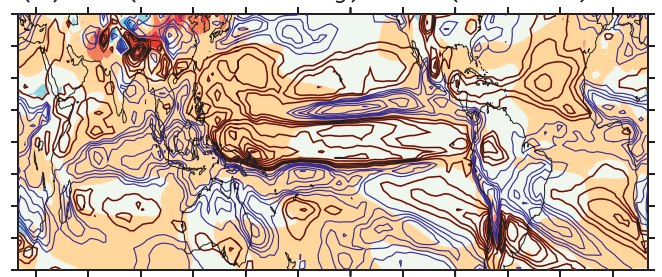

(f) $Q_{R}{ }^{*}$ (color shading), $L W_{C}{ }^{*}$ (contour)

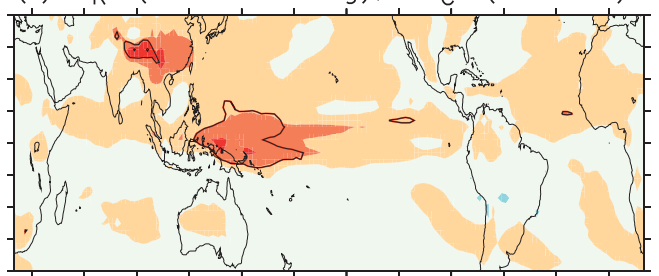

(h) Equatorial mean

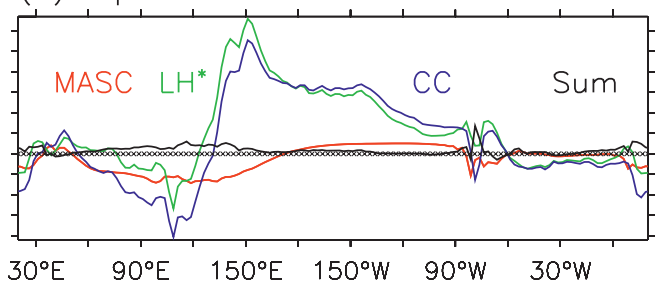

Zonal mean

(i) SUSI

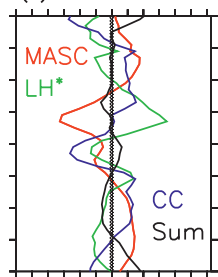

(j) $\mathrm{A} 1 \mathrm{~B}$

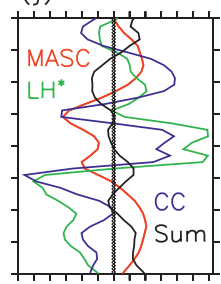

$\begin{array}{lll}-0.8 & 0.0 & 0.8\end{array}$
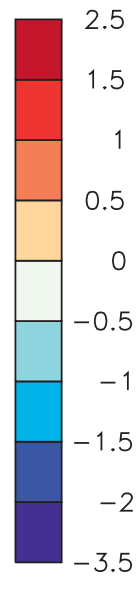

FIG. 3. Annual mean distributions (a)-(f) of 300-850-hPa-averaged terms in Eq. (3) in $0.1 \mathrm{~K}$ day $^{-1}$ (CI: $0.05 \mathrm{~K}^{-1 a y}{ }^{-1}$; 0 omitted), along with their $(\mathrm{g}),(\mathrm{h})$ equatorial means $5^{\circ} \mathrm{S}-5^{\circ} \mathrm{N}$ and (i),(j) zonal means in SUSI and A1B runs. In (c) and (d), $T^{*}$ and CC denote the warming patterns and circulation change terms, respectively. In (f), $\mathrm{SH}^{*}$ is unavailable in CM2.1 output, so instead, LWC* is plotted to show the relation between $\mathrm{QR}^{*}$ and $\mathrm{LH}^{*}$. In $(\mathrm{h}),(\mathrm{j})$, and hereafter, $\mathrm{LH}^{*}$ represents the combined effect of $\mathrm{LH}^{*}$ and $\mathrm{QR} *$ in $\mathrm{A} 1 \mathrm{~B}$ run. In $(\mathrm{g})-(\mathrm{j})$, sum means the summation of MASC, $\mathrm{LH}^{*}$, and CC to show their approximate balance [Eq. (4)].

effect is important for circulation change, as illustrated in Fig. 3 and the following sections.

Figures 3a-f show the relative importance of Eq. (3) terms in the GFDL models. For SUSI, the terms representing warming patterns (Fig. 3c), $\mathrm{SH}^{*}$, and $Q_{R}^{*}$ (Fig. $3 \mathrm{e})$ are negligible and the circulation change (Fig. $3 \mathrm{c}$ ) is largely in balance with the MASC and $\mathrm{LH}^{*}$ (Fig. 3a). For $\mathrm{A} 1 \mathrm{~B}$, the $Q_{R}^{*}$ effect is also significant (Fig. 3f). It features maxima in the western equatorial Pacific and the Tibetan Plateau, resembling the $\mathrm{LH}^{*}$ patterns $(r=$ 0.64). Our LBM experiment (not shown) indicates that the $Q_{R}^{*}$ effects are similar to the $\mathrm{LH}^{*}$ on changes of temperature, wind shear, Walker and Hadley circulation, albeit much weaker. Actually, the $Q_{R}^{*}$ is dominated by the $\mathrm{LW}_{C}^{*}(r=0.88$; Fig. $3 \mathrm{f})$, the cloud radiative effect associated with deep convection that produces $\mathrm{LH}^{*}$. They are combined and still denoted as $\mathrm{LH}^{*}$ in Figs. 3h,j and hereafter. Unavailable in the dataset, the $\mathrm{SH}_{\mathrm{A} 1 \mathrm{~B}}^{*}$ could be important in the boundary layer, but should be weak in the free troposphere. Thus, only the circulation change, MASC, and $\mathrm{LH}^{*}$ terms reach a magnitude of $0.1 \mathrm{~K} \mathrm{day}^{-1}$. Their sums are small for both runs (Figs. 3g-j), indicating that they are nearly balanced in the tropics.

By neglecting small terms (sensible and radiative heating), Eq. (3) can be further simplified as

$$
B \bar{\omega} \frac{\partial \theta_{*}}{\partial p}+B \omega^{\prime} \frac{\partial \bar{\theta}}{\partial p}=-B \bar{\omega} \frac{\partial\left\langle\theta^{\prime}\right\rangle}{\partial p}+\mathrm{LH}^{*} .
$$


By imposing MASC and $\mathrm{LH}^{*}$ diagnosed from the GCM output, LBM solves for both temperature patterns and circulation change including vertical motion.

\section{b. MASC mechanism}

Model simulations suggest that tropical tropospheric warming follows the moist adiabat in the vertical (Fig. 2), resulting in an increase in dry static stability $-\partial\langle\theta\rangle / \partial p$. With this upward-increasing atmospheric warming, the MASC mechanism refers to the cold/warm advection in climatological convective/subsidence regions. It is much smaller than $B \bar{\omega}\left(\partial \theta^{*} / \partial p\right)$ [Eq. (3)] for interannual variability, but is of great importance for global warming. This difference is caused by the fact that $O\left(\mathrm{SST}^{*}\right)$ $\left.\left\langle\mathrm{SST}^{\prime}\right\rangle\right) \gg 1$ for the former but $O\left(\mathrm{SST}^{*} /\left\langle\mathrm{SST}^{\prime}\right\rangle\right)<1$ for the latter.

The meridional structure of tropospheric warming in Fig. 2 suggests the importance of the MASC effect. In the midtroposphere (e.g., $600 \mathrm{hPa}$ ) in the subtropics $\left(20^{\circ}-30^{\circ}\right)$, the enhanced warming is anchored by the climatological subsidence, while the reduced warming over the equator by the mean upward motion. This feature is quite robust among CMIP3 models (see Fig. S2 of Lu et al. 2007). Similar collocations of the minimum in midtropospheric warming with convection and the maximum with subsidence centers can also be found in Fig. 1. Correlations between the annual mean warming patterns and climatological pressure velocity are 0.38 (Table 1 ). This correlation is moderate since the $\mathrm{LH}^{*}$ also affects the tropospheric warming patterns.

\section{c. Forcing distributions}

Besides LH*, MASC is a major forcing mechanism for the circulation response to global warming in the LBM [Eq. (4)]. Here we discuss the annual-mean tropical distributions of both terms in SUSI (Fig. 3a) and A1B (Fig. 3b) runs. The MASC follows the patterns of climatological vertical motion, which is similar but slightly different between the two runs, due to SST biases of the coupled model (A1B) compared to observations (SUSI; e.g., the double ITCZ bias; de Szoeke and Xie 2008). In both SUSI and A1B, $T^{*}$ features negative centers in the Indo-Pacific warm pool that extend to the ITCZ and SPCZ, and positive centers over subsidence regions (Fig. 1).

The $\mathrm{LH}^{*}$ distributions resemble the precipitation patterns and are quite different between the SUSI and A1B because of SST patterns in A1B (Xie et al. 2010). In the SUSI case, it is roughly opposite to the MASC $(r=-0.39)$. This is not coincident since the $\mathrm{LH}_{\mathrm{SUSI}}^{*}$ warms the convective region, representing the wet-get-wetter pattern of rainfall change, while the MASC cools the convective region by definition. The so-called upped-ante mechanism calls for reduced rainfall on the boundary between the warm pool and the equatorial cold tongue (Chou and Neelin 2004; Chou et al. 2009), reinforcing the MASC effect. Following rainfall patterns (Xie et al. 2010), the $\mathrm{LH}_{\mathrm{A} 1 \mathrm{~B}}^{*}$ distribution features a maximum on the equator with a peak in the western Pacific. The heating is greater in the Northern than the Southern Hemisphere. It is worth mentioning that with SST patterns, spatial variability in $\mathrm{LH}^{*}$ (precipitation) is greater in magnitude than in SUSI, especially clear in the equatorial and zonal means (Figs. 3g-j).

The equatorial forcing (Figs. 3g,h) is important for the Walker circulation change. Both the MASC and $\mathrm{LH}_{\text {SUSI }}^{*}$ (Fig. 3g) weaken the Pacific Walker cell, the latter due to the above-mentioned upped-ante mechanism. However, $\mathrm{LH}_{\mathrm{A} 1 \mathrm{~B}}^{*}$ (Fig. 3h) tends to accelerate the circulation, especially in the eastern Pacific, with a maximum effect at $140^{\circ} \mathrm{W}$.

The zonal mean forcing is important for the Hadley circulation changes. The MASC tends to weaken the Hadley circulation (Fig. 3i) by definition, cooling/ warming for upward/downward motions. By contrast, $\mathrm{LH}_{\text {SUSI }}^{*}$ accelerates the Hadley cell, consistent with the theory of Lindzen (1990). The MASC and $\mathrm{LH}_{\mathrm{SUSI}}^{*}$ almost balance each other in the deep tropics $(r=-0.77)$, but the MASC is slightly greater in the subtropics. The zonal mean $\mathrm{LH}_{\mathrm{A} 1 \mathrm{~B}}^{*}$ (Fig. 3j) is strongly influenced by SST patterns, especially the equatorial warming peak and the interhemispheric asymmetry with a greater SST increase north than south of the equator. The $\mathrm{LH}_{\mathrm{A} 1 \mathrm{~B}}^{*}$ has a negative correlation $(r=-0.55)$ with the MASC effect, but it is weaker than $\mathrm{LH}_{\text {SUSI }}^{*}$.

\section{d. Experimental designs}

In Eq. (4), MASC and $\mathrm{LH}^{*}$ are prescribed in the LBM as follows:

$$
\begin{aligned}
& \text { SUSI:MASC }+\mathrm{LH}_{\mathrm{SUSI}}^{*}, \quad \text { and } \\
& \begin{aligned}
\mathrm{A} 1 \mathrm{~B}: \mathrm{MASC}+\mathrm{LH}_{\mathrm{A} 1 \mathrm{~B}}^{*}= & \text { MASC }+\mathrm{LH}_{\mathrm{SUSI}}^{*} \\
& +\mathrm{LH}_{\mathrm{RAD}}^{*}+\mathrm{LH}_{\mathrm{SST}}^{*}
\end{aligned}
\end{aligned}
$$

Annual-mean MASC and $\mathrm{LH}^{*}$ are diagnosed from the SUSI and A1B runs. For the A1B run, LH* is further decomposed into components due to radiative forcing, SUSI, and SST patterns, as detailed in Table 2. By definition, MASC is likely to be similar among different models with some variations in model climatology. The latent heating term, and its subcomponents may differ substantially among models. See Xie et al. (2010) for a comparison between models developed at GFDL and the National Center of Atmospheric Research (NCAR). 
TABLE 2. Descriptions of the LBM experiments.

\begin{tabular}{|c|c|c|}
\hline Name & Forcing & Contribution \\
\hline MASC & MASC diagnosed from AM2.1 (SUSI) only & SUSI/A1B \\
\hline $\mathrm{LH}_{\mathrm{SUSI}}^{*}$ & LH* diagnosed from AM2.1 (SUSI) only & SUSI/A1B \\
\hline MASC + LH $_{\text {SUSI }}^{*}$ & MASC and LH* diagnosed from AM2.1 (SUSI) & SUSI/A1B \\
\hline $\mathrm{LH}_{\mathrm{SST}}^{*} \quad$ sUS1 & $\mathrm{LH}^{*}$ of CM2.1 (A1B)-AM2.1 (SUSI)-RAD & A1B \\
\hline $\mathrm{LH}_{\mathrm{A} 1 \mathrm{~B}}^{*}$ & $\mathrm{LH}^{*}$ diagnosed from CM2.1 (A1B) only & A1B \\
\hline $\mathrm{MASC}+\mathrm{LH}_{\mathrm{A} 1 \mathrm{~B}}^{*}$ & MASC and LH* diagnosed from CM2.1 (A1B) & A1B \\
\hline
\end{tabular}

We linearize the LBM around the annual mean climatology of AM2.1 during 1983-91 for the SUSI-related experiments, and that of CM2.1 during 1996-2005 for the A1B ones. We integrate the model for 60 days to equilibrium. Since the LBM does not represent the synoptic eddy-mean flow interaction properly, we restrict the thermodynamic forcing in $40^{\circ} \mathrm{S}-40^{\circ} \mathrm{N}$.

\section{General survey of tropospheric temperature and wind shear changes}

This section presents the LBM response to individual and combined forcing factors in Eqs. (5) and (6) and compares the results with the GCMs. Besides the tropospheric warming patterns, the vertical wind shear changes are examined in both vector and magnitude of absolute zonal wind shear $\left(\left|U_{300}-U_{850}\right|\right)$ change.

Figure 4 shows the results for the SUSI run. As one expects, the MASC (Fig. 4a) cools the deep tropics, especially the tropical Pacific, while it warms the subtropical subsidence regions. The MASC response is generally symmetric about the equator. Consistent with the thermal-wind relation, the tropical tropospheric wind shear is reduced almost everywhere. By contrast, $\mathrm{LH}_{\text {SUSI }}^{*}$ (Fig. 4b) tends to warm the tropics and cool the subtropics, especially in the South Pacific, causing wind shear to increase in the subtropical Pacific and the tropical Atlantic region of frequent cyclone development (Vecchi and Soden 2007c). The MASC and $\mathrm{LH}_{\mathrm{SUSI}}^{*}$ responses oppose each other and the spatial correlation is -0.69 for tropospheric temperature and -0.4 for wind shear (Table 3). In the central and eastern equatorial Pacific, however, $\mathrm{LH}_{\mathrm{SUSI}}^{*}$ reduces the wind shear, apparently due to the upped-ante cooling to the west of the climatological equatorial cold tongue (Fig. 3a). LBM simulations forced by observed diabatic heating have been very successful in capturing circulation change associated with natural variability such as ENSO. If one was to do the same for global warming as in the SUSI run, he/she would be surprised that the simulated circulation change (a) MASC

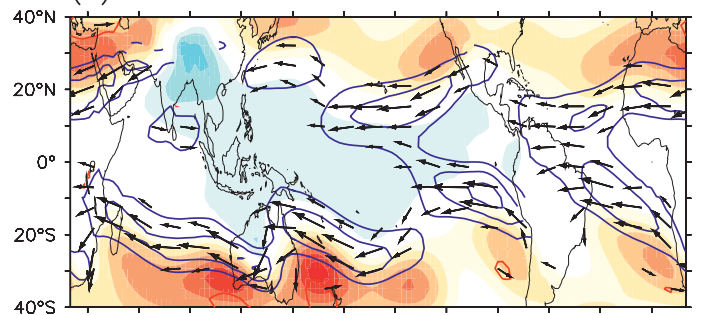

(c) MASC $+\mathrm{LH}^{*}$ SUSI

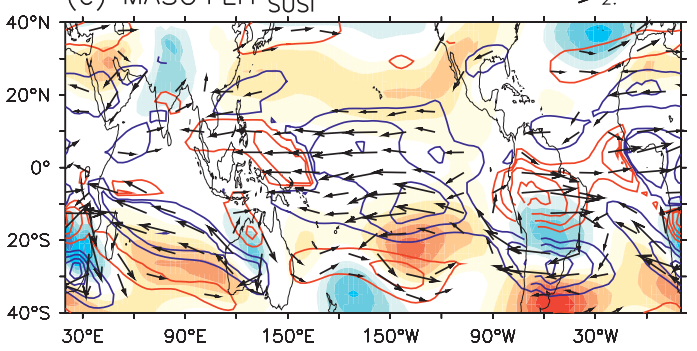

(b) $\mathrm{LH}^{*}$ SUSI

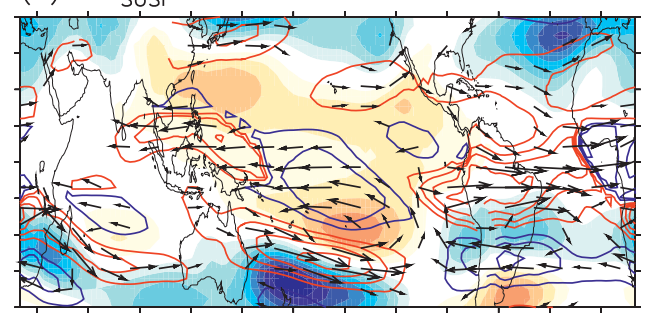

(d) AM2.1

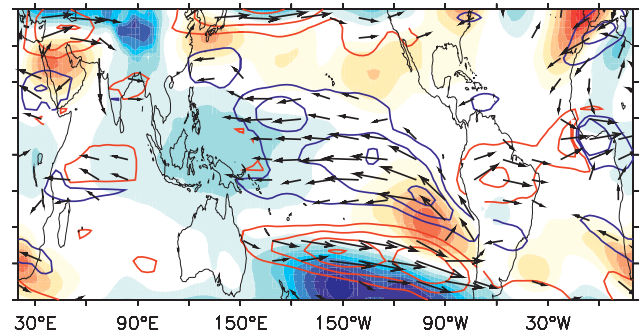

(e) Zonal mean $\mathrm{T}^{*}$

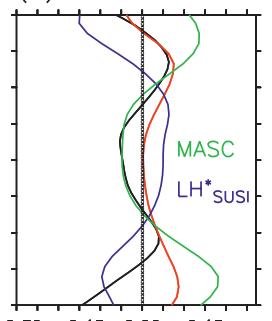

$\begin{array}{llll}-0.30 & -0.15 & 0.00 & 0.15\end{array}$

(f) Zonal wind shear

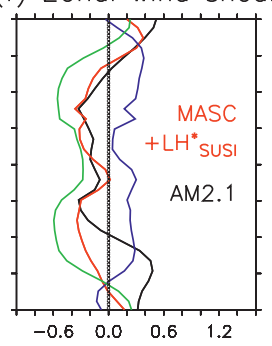

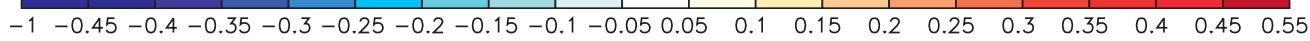

FIG. 4. The 300-850-hPa-averaged air temperature warming patterns (color shading, K), wind shear (vectors, $\mathrm{m} \mathrm{s}^{-1}$ ), and absolute zonal wind shear (contours, CI: $0.5 \mathrm{~m} \mathrm{~s}^{-1} ; 0$ omitted) changes in LBM forced by annual mean (a) MASC, (b) LH $\mathrm{SUSI}_{\text {, and (c) MASC + LH }}^{*}$, compared with (d) AM2.1. The zonal means of the (e) warming patterns and (f) absolute shear change. 
TABLE 3. Spatial correlation coefficient $\left(r, 40^{\circ} \mathrm{S}-40^{\circ} \mathrm{N}\right)$ of annual mean 300-850-hPa-averaged air temperature warming patternsabsolute zonal wind shear (ash) change among LBM and GFDL models.

\begin{tabular}{ccrccc}
\hline $\begin{array}{c}r\left(40^{\circ} \mathrm{S}-40^{\circ} \mathrm{N}\right) \\
x-y / \text { zm }\end{array}$ & MASC & LH $_{\text {SUSI }}^{*}$ & LH $_{\text {SST }}^{*}$ & $\begin{array}{c}\text { MASC }+ \\
\text { LH }_{\text {SUSI }}^{*}\end{array}$ & $\begin{array}{c}\text { MASC }+ \\
\text { LH }_{\text {A1B }}^{*}\end{array}$ \\
\hline$\left.T_{\text {va }}^{*}\right|_{\text {AM2.1 }}$ & 0.14 & 0.13 & - & 0.34 & - \\
$\left.U_{\text {ash }}^{\prime}\right|_{\text {AM2.1 }}$ & 0.19 & 0.09 & & 0.53 & \\
$\left.T_{\text {va }}^{*}\right|_{\text {CM2.1 }}$ & 0.21 & 0.48 & - & 0.64 & - \\
$\left.U_{\text {ash }}^{\prime}\right|_{\text {CM2.1 }}$ & 0.70 & -0.32 & & 0.69 & \\
$\left.T_{\text {val }}^{*}\right|_{\text {MASC }}$ & 0.19 & -0.16 & 0.60 & 0.01 & 0.62 \\
$\left.U_{\text {ash }}^{\prime}\right|_{\text {MASC }}$ & 0.01 & -0.23 & 0.48 & 0.06 & 0.76 \\
& - & -0.69 & 0.43 & 0.24 & 0.61 \\
& & -0.85 & -0.54 & 0.07 & 0.55 \\
\hline
\end{tabular}

is almost opposite to the GCM results. This illustrates the importance of MASC.

The combined MASC and $\mathrm{LH}_{\text {SUSI }}^{*}$ response (Fig. 4c) resembles the AM2.1 (SUSI) results (Fig. 4d), with spatial correlation for tropospheric temperature/wind shear changes at $r=0.34-0.64$. This illustrates the skills of LBM in simulating the circulation response to global warming. The magnitude of LBM results is slightly weaker than that of AM2.1, possibly due to the arbitrarily set damping and horizontal diffusion. The tropospheric cooling in the midlatitude South Pacific is not strong enough in the LBM, possibly related to eddy effects. The peaks of subtropical warming by $\mathrm{LH}_{\text {SUSI }}^{*}$ (Fig. 4b) are slightly shifted to lower latitudes than in AM2.1 (Fig. 4d), and the MASC (Fig. 4a) helps to adjust them to the right positions (Fig. 4c). The cooling over the Tibetan Plateau is due to the MASC (Figs. 4a,c,d) associated with orographic convection anchored by the Himalayas and advected by the westerly jet stream. The tropical Pacific wind shear is generally reduced (Figs. 4c,d), with the contributions from $\mathrm{LH}_{\mathrm{SUSI}}^{*}$ in the central Pacific basin (Fig. 4b) and from MASC effect in the subtropics (Fig. 4a).

The zonal means better illustrate the importance of MASC. The MASC and $\mathrm{LH}_{\text {SUSI }}^{*}$ effects (Fig. 4e) are both symmetric about the equator, and oppose each other $(r=-0.85)$. Their combined (MASC $\left.+\mathrm{LH}_{\text {SUSI }}^{*}\right)$ effect follows the MASC response, and resembles the AM2.1 results $(r=0.53)$ to the north of $20^{\circ} \mathrm{S}$. For the wind shear change (Fig. 4f), the MASC effect again opposes the $\mathrm{LH}_{\text {SUSI }}^{*}$ effect, with $r=-0.66$ (Table 3). Primarily following the shape of MASC, the total effect weakens the tropical wind shear, resembling the AM2.1 results $(r=0.69)$. It is noteworthy that the MASC effects flip sign at around $30^{\circ} \mathrm{S}$ and $30^{\circ} \mathrm{N}$ (Fig. 4f), where the climatological wind shear/meridional temperature gradients are strongest. This is equivalent to a poleward shift of the jet streams-expansion of the Hadley cell, consistent with the argument of Fu et al. (2006).

For the A1B run, the $\mathrm{LH}^{*}$ effects include components induced by RAD and SST patterns. The RAD effect (Fig. 5a), with the prescribed SST, is much smaller than the SST pattern effect, with a modest contribution over the midlatitude Eurasian and North American continents. It hardly affects the Pacific Walker circulation but reduces wind shear in the western tropical Indian Ocean. The RAD influence on the Hadley circulation is weak in zonal mean (Fig. 5e), but reinforces the MASC (Fig. 4e), with $r=0.62$. The SST patterns have a significant influence on the interhemispheric asymmetry of tropospheric warming (Figs. 5b,e). The SST patterns enhance wind shear in the eastern equatorial Pacific, South Pacific, and South Atlantic, but reduce it in the eastern tropical Indian Ocean, western equatorial Pacific, tropical North Pacific, and tropical North Atlantic (Figs. 5c-e). The LBM response to SST patterns is too strong compared to the wind shear change in CM2.1 (Fig. 5d).

The comparison of LBM results with CM2.1 is greatly improved (Table 3) from MASC $+\mathrm{LH}_{\text {SUSI }}^{*}$ (Fig. 4c) to MASC $+\mathrm{LH}_{\mathrm{A} 1 \mathrm{~B}}^{*}$ (Fig. 5c). The reduction in wind shear over the tropical Indian Ocean is a major difference between SUSI (Figs. 1a and 4d) and A1B (Figs. 1b and 5d), due to both RAD and SST effects. Likewise the increased wind shear in the eastern tropical North Pacific is due to the SST patterns. The MASC effect is most pronounced in the Northern Hemisphere, helping to maintain the cooling in the deep tropics and the associated wind shear reduction in the North Pacific (Figs. 4c,e and 5b,c,e). The combined MASC $+\mathrm{LH}_{\mathrm{A} 1 \mathrm{~B}}^{*}$ effect increases the correlation with $\mathrm{CM} 2.1$ by 0.2 compared to the $\mathrm{LH}_{\mathrm{A} 1 \mathrm{~B}}^{*}$ effect.

The MASC effect is much weaker than LH in interannual variability of the atmosphere, but the above analyses show that it is important in global warming. Specifically, the MASC mechanism acts to reduce tropical tropospheric meridional temperature gradients and zonal wind shear. Along with the wet-get-wetter mechanism (Chou and Neelin 2004), the MASC is an important mechanism of pattern formation when SST warming is spatially uniform.

\section{Overturning circulations}

This section examines the forcing factors for overturning circulation changes based on LBM simulations and comparison with GCMs.

\section{a. Walker circulation}

Upper-tropospheric velocity potential $(\chi)$ was used to diagnose the large-scale atmospheric circulation 
(a) RAD

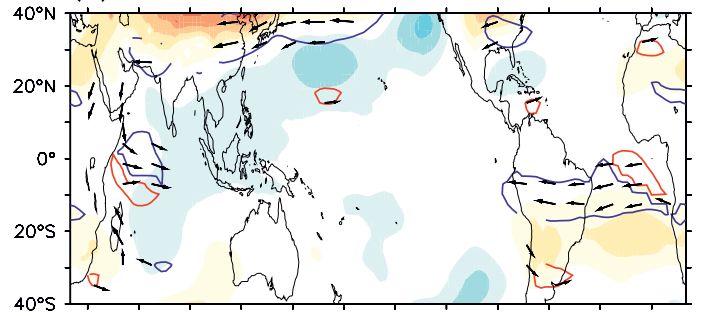

(c) $\mathrm{MASC}+\mathrm{LH}^{*}{ }_{\mathrm{A} 1 \mathrm{~B}}$

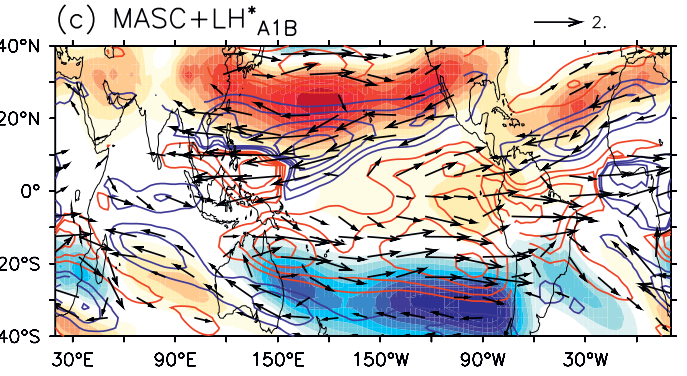

(b) $\mathrm{LH}^{*}$ SST

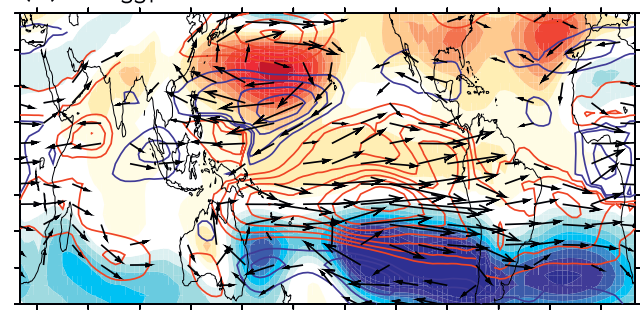

(d) CM2.1

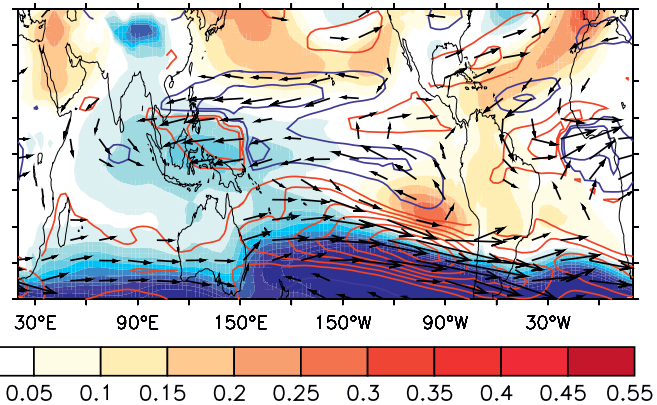

(e) Zonal mean $T^{*}$

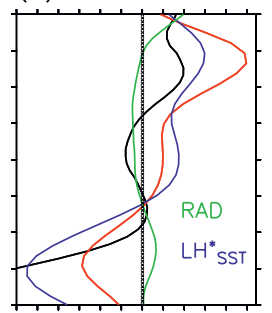

$\begin{array}{llll}-0.30 & -0.15 & 0.00 & 0.15\end{array}$

(f) Zonal wind shear

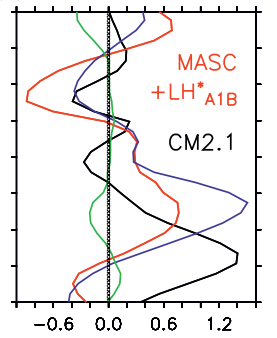

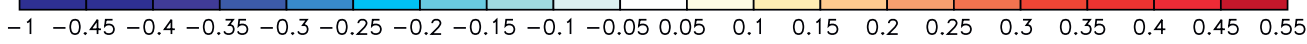

FIG. 5. As in Fig. 4, but for changes in (a) RAD, LBM forced by annual mean (b) $\mathrm{LH}_{\mathrm{SST}}^{*}$, and (c) $6 \mathrm{MASC}+\mathrm{LH}_{\mathrm{A} 1 \mathrm{~B}}^{*}$, compared with (d) CM2.1.

(Gastineau et al. 2009). We calculate $\chi$ at the 250-hPa level to characterize the change of the Walker circulation, by solving the following Poisson equation on the globe (Tanaka et al. 2004):

$$
\nabla \cdot \mathbf{V}=-\Delta \chi
$$

where $\mathbf{V}$ is wind velocity. Figures $6 \mathrm{a}-\mathrm{h}$ show the horizontal distributions of the changes in $250 \mathrm{hPa} \chi$ (color shading) and divergent wind (vectors) in response to various forcing factors. The climatological mean (contours) features the Pacific Walker circulation with divergence/convergence (negative/positive $\chi$ ) on the western/eastern basins.

The MASC (Fig. 6a) tends to reduce the divergence/ upward motion over the Indo-Pacific warm pool, by its adiabatic cooling effect illustrated in Fig. 3. By contrast, $\mathrm{LH}_{\text {SUSI }}^{*}$ (Fig. 6b) induces divergence over the eastern Pacific, due to the heating peak there (Fig. 3a), and weak convergence at $170^{\circ} \mathrm{E}$ (Fig. 6i), due to the upped-ante mechanism. Even without any SST gradient, the MASC and $\mathrm{LH}_{\mathrm{SUSI}}^{*}$ act together to slow down the Walker circulation over the vast area of the Pacific (Figs. 6e,f). High spatial correlation $(r=0.78$, Table 4$)$ appears between MASC $+\mathrm{LH}_{\mathrm{SUSI}}^{*}$ and AM2.1. The $\chi$ on the equator (Fig. 6i), representing the Walker circulation, shows that the MASC reduces the zonal wind between $130^{\circ} \mathrm{E}$ and $130^{\circ} \mathrm{W}$, while the $\mathrm{LH}_{\text {SUSI }}^{*}$ reduces it in $130^{\circ}-90^{\circ} \mathrm{W}$. The higher correlation with AM2.1 of MASC (0.74) than of $\mathrm{LH}_{\text {SUSI }}^{*}(0.55)$ indicates the MASC effect is key to the success of LBM simulation of the weakened Walker circulation $\left(r=0.87\right.$ for MASC $\left.+\mathrm{LH}_{\mathrm{SUSI}}^{*}\right)$.
For changes in A1B, the RAD slightly strengthens the Walker circulation (Figs. 6c,j). The peak of SST warming in the midequatorial Pacific (Fig. 3b), contribute to a divergence center at $175^{\circ} \mathrm{E}$ in the central Pacific (Figs. $6 \mathrm{~d}, \mathrm{j})$, reducing the Walker circulation over the western Pacific but accelerating it in the eastern basin. Primarily maintained by the MASC, the zonal wind reduction of MASC $+\mathrm{LH}_{\mathrm{A} 1 \mathrm{~B}}^{*}$ extends to $140^{\circ} \mathrm{W}$ (Figs. 6g,j) and is almost identical to CM2.1 (Figs. 6h,j), with very high spatial correlation (0.94) especially on the equator (0.97).

Thus, the MASC is very important for the weakening of the Walker circulation, even more so in the A1B simulation. It has essential effect over the west-tomidequatorial Pacific. The SST contribution to $\chi$ is strong over the entire Pacific, but its accelerating effect is opposed by the MASC to the west of $140^{\circ} \mathrm{W}$. Considering SST patterns of CM2.1 are among the strongest [the spatial standard deviation is $0.24 \mathrm{~K}(\mathrm{~K})^{-1}$ tropical mean warming, as compared to the CMIP3 model ensemble of $0.17 \pm 0.05 \mathrm{~K}(\mathrm{~K})^{-1}$ ], the strong MASC effect explains that the weakening of the Walker cell is very robust among the CMIP3 models (Vecchi and Soden 2007a).

\section{b. Hadley circulation}

We investigate mechanisms for Hadley circulation change, which is represented by the zonal-integrated meridional mass streamfunction ( $\psi$, Fig. 7$)$, and by the zonal mean $250-\mathrm{hPa} \chi$ (Figs. 6k,l). Figure 7 shows the climatological annual mean Hadley circulation in contours, which features a clockwise/anticlockwise 
(a) MASC

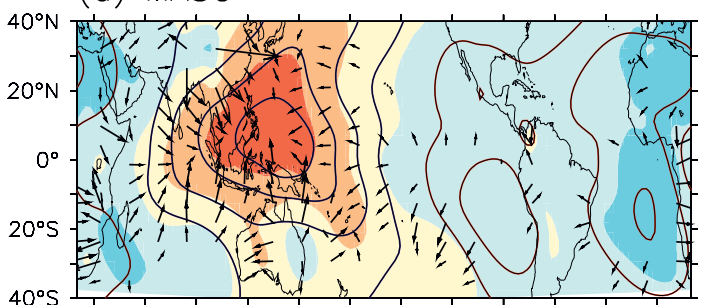

(c) RAD

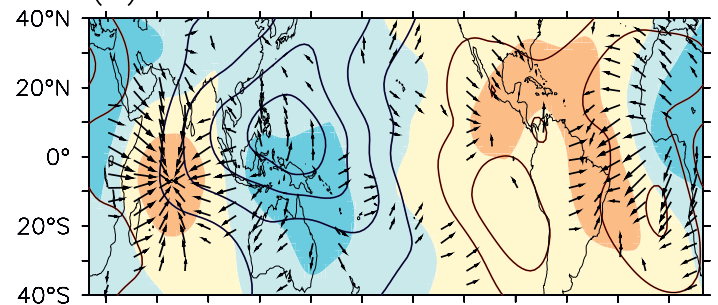

(e) MASC $+\mathrm{LH}^{*}$ SUSI

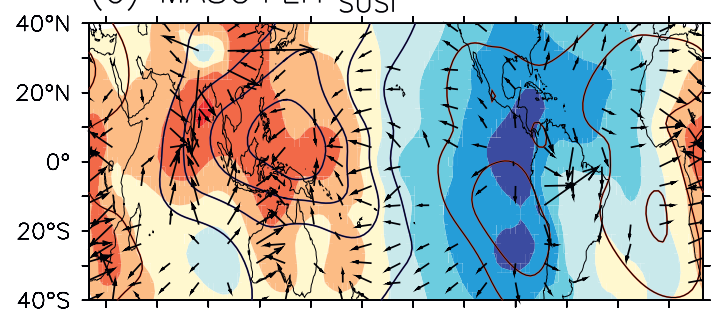

(g) $\mathrm{MASC}+\mathrm{LH}^{*}{ }_{\mathrm{A} 1 \mathrm{~B}}$

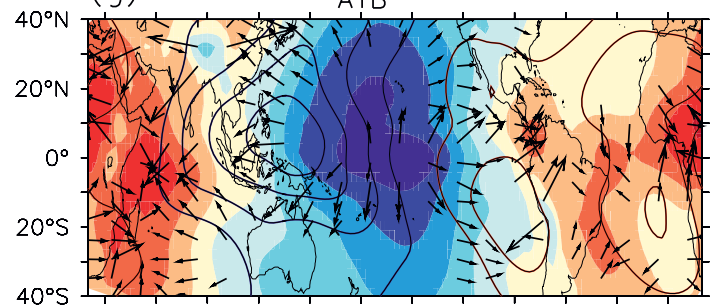

(i) Equatorial mean (15S-15N)

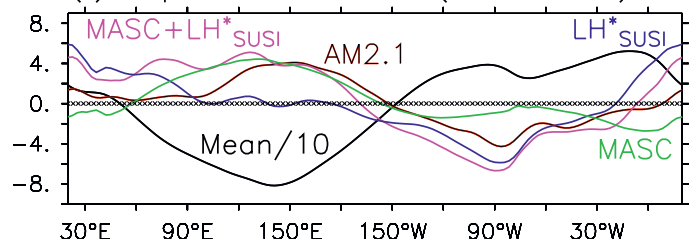

(b) $\mathrm{LH}^{*}$ SUSI

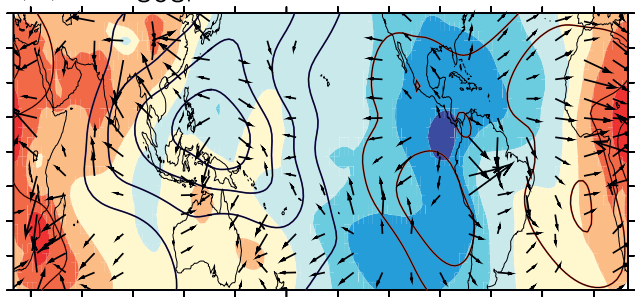

(d) $\mathrm{LH}^{*} \mathrm{SST}$

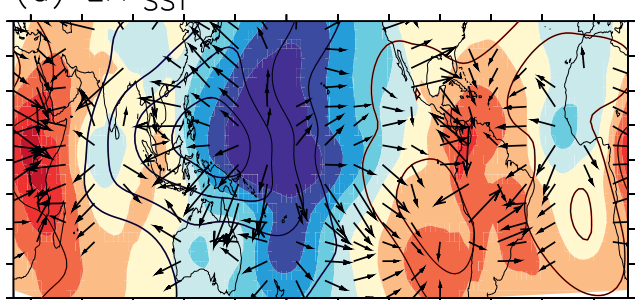

(f) AM2.1

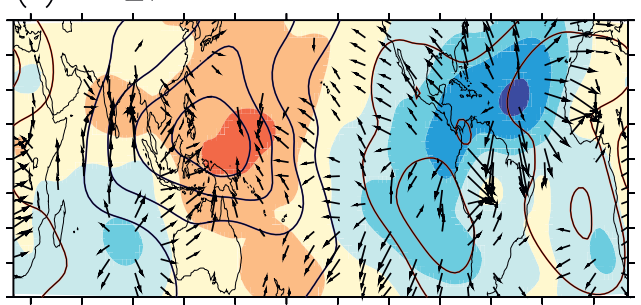

(h) $\mathrm{CM} 2.1$

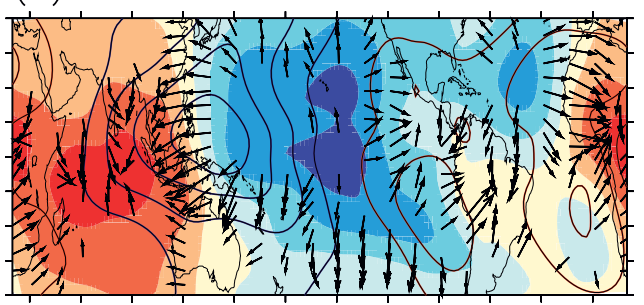

(j) Equatorial mean (15S-15N)

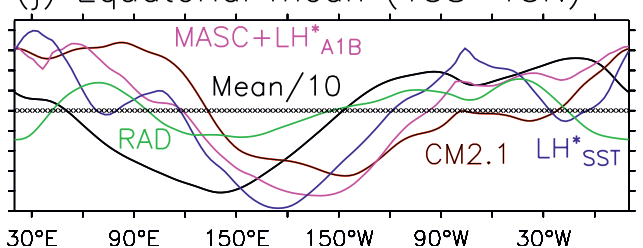

(k) Zonal mean

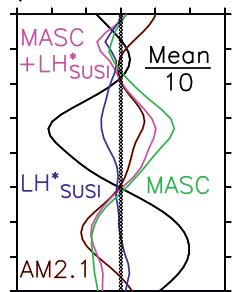

(I) Zonal mean

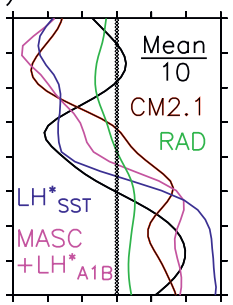

-1 . 0.1 .

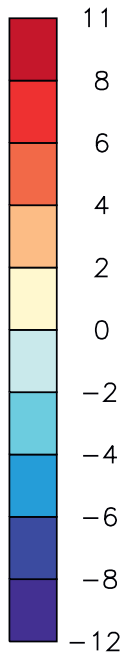

$\longrightarrow 0.5$

$250 \mathrm{hPa}$

Velocity

Potential

$10^{5} \mathrm{~m}^{2} \mathrm{~s}^{-1}$

FIG. 6. (a)-(h) Annual mean changes of $250-\mathrm{hPa}$ velocity potential $\left(10^{5} \mathrm{~m}^{2} \mathrm{~s}^{-1}\right)$ distribution (color shading) with the (i),(j) equatorial means and (k),(l) zonal means. In (a)-(h), vectors are the changes of divergent wind $\left(\mathrm{m} \mathrm{s}^{-1}\right)$, and contours $\left(\mathrm{CI}: 20 \times 10^{5} \mathrm{~m}^{2} \mathrm{~s}^{-1}\right.$; 0 omitted) show the mean velocity potential for reference.

tropical cell (positive/negative values of $\psi$ ) in the Northern/Southern Hemisphere, with upward motion over the ITCZ $\left(\sim 5^{\circ} \mathrm{N}\right)$ and subsidence in the subtropics $\left(20^{\circ}-40^{\circ}\right)$.

The MASC forces a significant weakening of the Hadley circulation (Figs. $7 \mathrm{a}$ and $6 \mathrm{k}$ ), while $\mathrm{LH}_{\mathrm{SUSI}}^{*}$ accelerates it (Figs. $7 \mathrm{~b}$ and $6 \mathrm{k}$ ) at a reduced magnitude. The combined effect follows the MASC patterns $(r=0.43$ for $\psi$ and 0.66 for $\chi)$ and is quite similar $(r \geq 0.67)$ between the LBM (Figs. 7e and 6k) and AM2.1 (Figs. 7f and $6 \mathrm{k}$ ). Thus, the MASC is the major driver for the Hadley circulation reduction in the AM2.1 SUSI experiment. Although the $\mathrm{LH}_{\text {SUSI }}^{*}$ effect is weak here, its sign is always opposite to the MASC.

In response to GHG increase, the RAD effect causes a weak reduction in the Hadley cell in the Northern 
TABLE 4. Spatial correlation coefficient $\left(r, 40^{\circ} \mathrm{S}-40^{\circ} \mathrm{N}\right)$ of annual mean changes of $250-\mathrm{hPa}$ velocity potential $(\chi)$ and meridional streamfunction $(\psi)$ among LBM and GFDL models. The em denotes equatorial mean $\left(15^{\circ} \mathrm{S}-15^{\circ} \mathrm{N}\right)$.

\begin{tabular}{ccrccc}
\hline $\begin{array}{c}r\left(40^{\circ} \mathrm{S}-40^{\circ} \mathrm{N}\right) \\
x-y / \mathrm{em} / \mathrm{zm}\end{array}$ & MASC & LH $_{\text {SUSI }}^{*}$ & LH $_{\text {SST }}^{*}$ & $\begin{array}{c}\text { MASC } \\
\text { LH }_{\text {SUSI }}^{*}\end{array}$ & $\begin{array}{c}\text { MASC }+ \\
\text { LH }_{\text {A1B }}^{*}\end{array}$ \\
\hline$\left.\chi\right|_{\text {AM2.1 }}$ & 0.62 & 0.45 & - & 0.78 & - \\
& 0.74 & 0.55 & & 0.87 & \\
& 0.66 & -0.48 & & 0.68 & \\
$\left.\chi\right|_{\text {CM2.1 }}$ & -0.11 & 0.68 & 0.57 & 0.54 & 0.94 \\
& 0.03 & 0.67 & 0.65 & 0.53 & 0.97 \\
$\left.\chi\right|_{\text {MASC }}$ & -0.20 & 0.48 & 0.81 & -0.09 & 0.94 \\
& - & -0.14 & -0.54 & - & - \\
$\psi$ & & 0.05 & -0.48 & & \\
$\left.\psi\right|_{\text {AM2.1 }}$ & 0.43 & 0.08 & - & 0.67 & - \\
$\left.\psi\right|_{\text {MAS2 }}$ & -0.25 & 0.45 & 0.62 & 0.14 & 0.88 \\
\hline
\end{tabular}

Hemisphere (Figs. 7c and 61), with the same sign as the MASC. The SST patterns (specifically the equatorial peak, Fig. 3b) induce an anomalous cell on either side of the equator (Fig. 7d), with a meridional scale of the equatorial Rossby radius of deformation $\left(\sim 15^{\circ}\right)$. This corresponds to an acceleration of the Hadley cell near the equator in response to the equatorial peak in SST warming (Liu et al. 2005; Xie et al. 2010). Because the SST warming is greater in the Northern than the Southern Hemisphere (Fig. 3b), the Northern SSTinduced equatorial cell is weak, especially above $500 \mathrm{hPa}$ and the Hadley cell is reduced in the northern off-equatorial region. As a result, only the southern cell intensification is visible in the upper troposphere (Fig. 61).

The total effect of the four factors (MASC $+\mathrm{LH}_{\mathrm{A} 1 \mathrm{~B}}^{*}$, Fig. $7 \mathrm{~g}$ ) explains the CM2.1 changes (Fig. 7h) quite well $(r=0.88)$. The Hadley cell weakens in the Northern Hemisphere and accelerates in the Southern Hemisphere. For the Northern Hemispheric cell, the SSTinduced acceleration is offset by the $\mathrm{LH}_{\mathrm{SUSI}}^{*}$, while both the MASC and RAD effects contribute to the reduction. In the Southern Hemisphere, the SST-induced cell dominates over the MASC $+\mathrm{LH}_{\text {SUSI }}^{*}$ effect, accelerating the Hadley cell.

The LBM experiments indicate that the SST-patterninduced LH effect explains the difference in the Hadley cell changes between AM2.1 and CM2.1, shedding light on the intermodel variations in CMIP3 models (Fig. 8). The CMIP3 ensemble-mean change in the 500-hPa $\psi$ shows a general reduction of the Hadley circulation intensity in off-equatorial regions. Large intermodel variability appears in $15^{\circ} \mathrm{S}-15^{\circ} \mathrm{N}$ due to difference in SST patterns. This uncertainty can alter the sign of the Hadley circulation change in the Southern Hemisphere, but not in the Northern Hemisphere, because of stronger ensemble-mean reduction of the Hadley cell in the Northern than in the Southern Hemisphere. This is due to the south-north gradient in ensemble mean SST warming (Lu et al. 2008; Vecchi and Soden 2007a). Near the equator, the ensemble mean $\psi$ change appears flat relative to the AM2.1 SUSI result, due to the equatorial peak in ensemble-mean SST warming (Liu et al. 2005; Lu et al. 2008). Thus, although much weaker than the CM2.1 $\mathrm{A} 1 \mathrm{~B}$, which is apparently an outlier among the CMIP3 models, the meridional variation in ensemble mean SST change affects the ensemble mean $\psi$ change, dragging it from AM2.1 SUSI-like toward CM2.1 A1B-like patterns.

We examine the relationship between the SST patterns and Hadley cell strength change among the CMIP3 models by performing two sets of intermodel SVD analysis. One is between the zonal mean SST and the 500-hPa $\psi$, and the other is between the zonal mean precipitation (representing LH) and the $500-\mathrm{hPa} \psi$. Specifically, a conventional SVD analysis is applied to 23 pairs of the variables simulated by the 23 CMPI 3 models. Since the primary modes of $\psi$ are nearly identical in the two analyses, their mean is presented in Fig. 9.

The first SVD mode (Fig. 9a) is antisymmetric with positive/negative anomalous SST and precipitation in the Northern/Southern Hemisphere. The intermodel variability in meridional SST gradient is accompanied by a cross-equatorial anticlockwise circulation between $15^{\circ} \mathrm{S}$ and $15^{\circ} \mathrm{N}$ that represents a strengthened/weakened Hadley cell to the south-north of the equator. The second mode (Fig. 9b) is symmetric and features a doublecell circulation within $20^{\circ} \mathrm{S}-20^{\circ} \mathrm{N}$ that is driven by the equatorial peak of SST and represents strengthened Hadley circulation at either side of the equator. Although not participating in the SVD analysis, the 10-member ensemble mean change in the CM2.1 can be reconstructed quite well by a linear combination of these two leading covariant components. Figure $9 \mathrm{c}$ shows that the reconstructions capture the large-scale latitudinal variations of the deviations of the CM2.1 results from the CMIP3 ensemble means, with $r=0.92$ and 0.93 for SST and $\psi$, respectively. This cross validation supports our LBM result that the SST pattern effect is important for Hadley circulation change.

The above analyses show that the MASC is a fundamental mechanism for the slowdown of both the Walker and Hadley circulations even without any SST gradient change (SUSI). For the Hadley cell, it is the only weakening mechanism. Since the meridional variations of SST warming in CM2.1 are among the strongest of the CMIP3 models, especially between the equator and the Southern Hemisphere, they dominate the southern Hadley cell change. The Northern Hadley cell decelerates mostly due to the MASC. 
(a) MASC

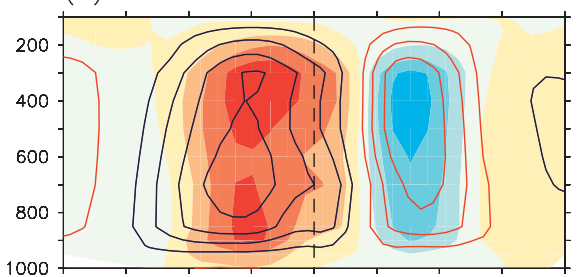

(c) RAD

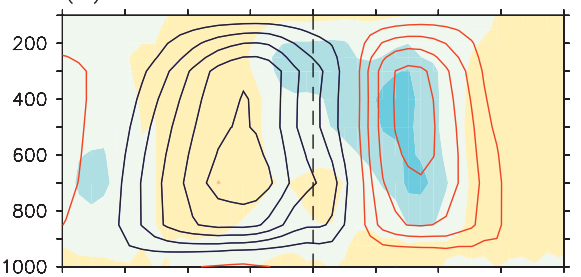

(e) MASC $+\mathrm{LH}^{*}$ SUSI

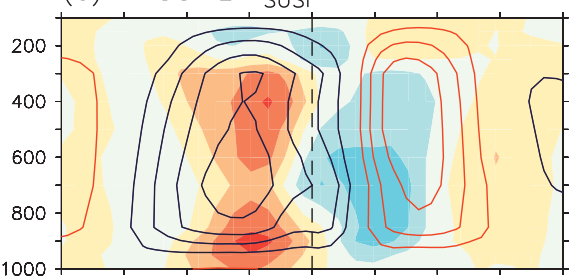

(g) $\mathrm{MASC}+\mathrm{LH}^{*}{ }_{\mathrm{A} 1 \mathrm{~B}}$

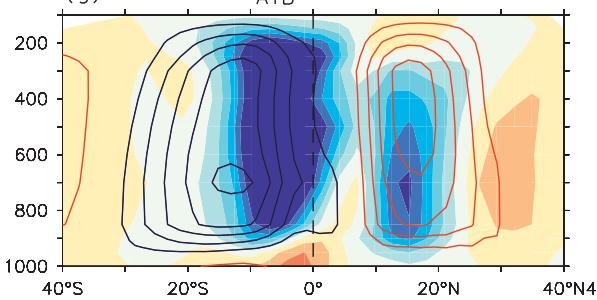

(b) $\mathrm{LH}^{*}$ SUSI

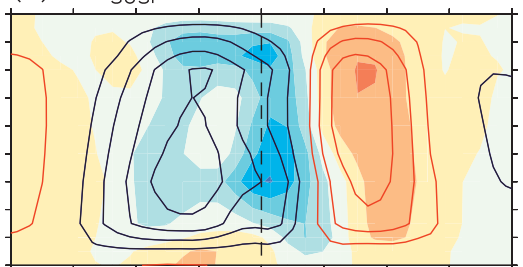

(d) $\mathrm{LH}^{*}{ }_{\mathrm{SST}}$

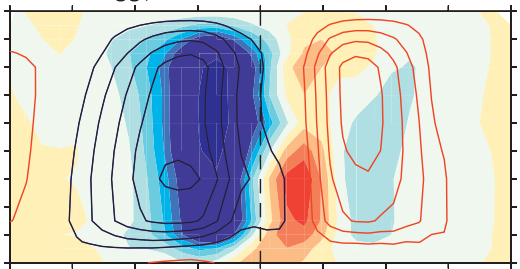

(f) $\mathrm{AM} 2.1$

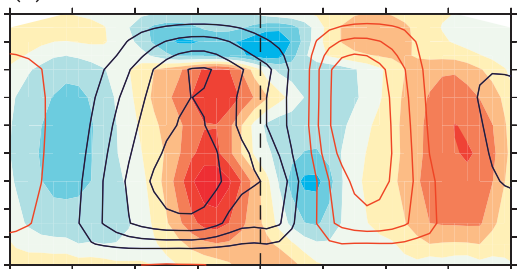

(h) $\mathrm{CM} 2.1$

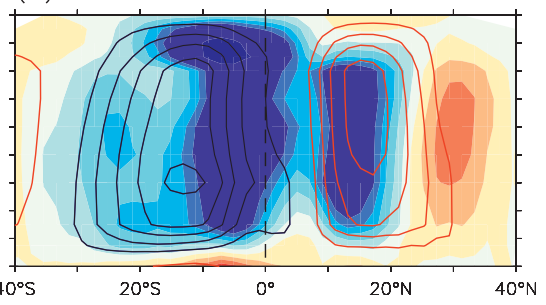

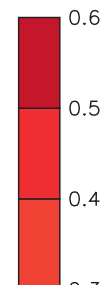

0.3
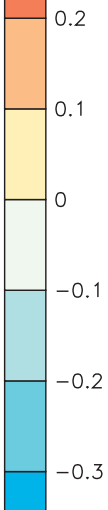

$-0.3$

$-0.4$

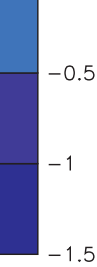

FIG. 7. Annual mean changes of the Hadley circulation presented by the zonal-integrated meridional streamfunction (color shading, $10^{10} \mathrm{~kg} \mathrm{~s}^{-1}$ ) with the contours (CI: $2 \times 10^{10} \mathrm{~kg} \mathrm{~s}^{-1} ; 0$ omitted) showing the mean circulation for reference.

\section{Conclusions and discussion}

Based on a series of LBM simulations, this study shows that the MASC mechanism is crucial in weakening the tropical atmospheric circulation (including the Walker and Hadley cells and vertical shear) and reducing the meridional temperature gradients of the tropical troposphere. The MASC effect arises from adiabatic cooling/heating due to the vertical advection by climatological upward/downward motion on a background of global increase in static stability. MASC is an important mechanism for circulation adjustment to global warming.

We have developed a diagnostic framework that employs the LBM to understand the tropospheric circulation change in global warming by decomposing thermodynamic forcing (TF) on the right-hand sides of Eqs. (5) and (6) into the following terms:

$$
\mathrm{TF}=\mathrm{MASC}+\mathrm{LH}_{\mathrm{SUSI}}^{*}+\mathrm{LH}_{\mathrm{RAD}}^{*}+\mathrm{LH}_{\mathrm{SST}}^{*}
$$

Our results demonstrate the LBM's utility in global warming pattern studies to quantify the relative importance of various forcing factors. Global warming features a nearly horizontal-uniform increase of tropospheric temperature. The MASC is important in tropical circulation adjustment, comparable in magnitude to the $\mathrm{LH}_{\mathrm{SUSI}}^{*}$ and SST pattern effects, while the RAD effect is much weaker. In interannual variability, the ratio of the tropical mean-standard deviation for the SST anomaly drops to $\sim 1 / 7$ (see the introduction), the MASC and $\mathrm{LH}_{\mathrm{SUSI}}^{*}$ effects become much weaker than the SST pattern effect, and the effect of SST-pattern-induced LH dominates the tropical circulation anomalies. This is a fundamental distinction between interannual variability and global warming. 


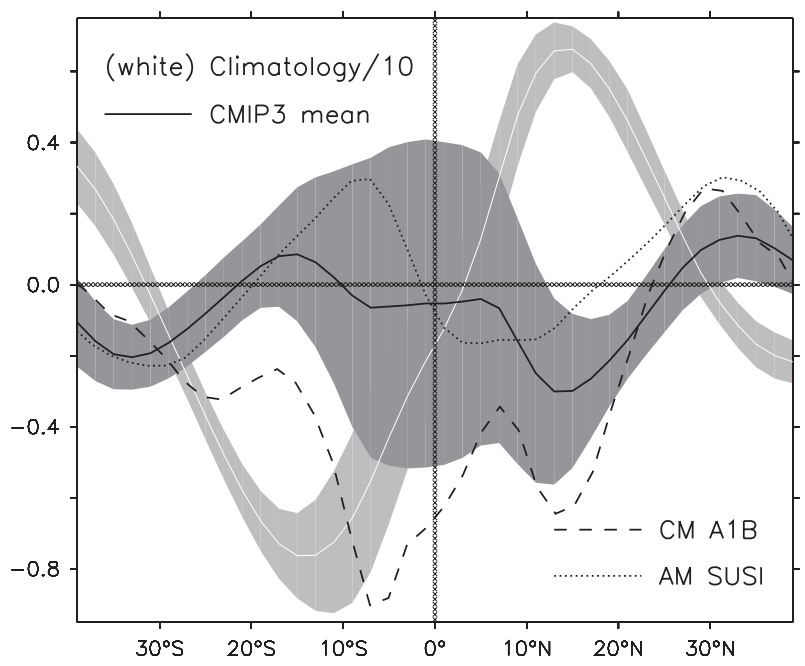

FIG. 8. Annual mean climatology and changes of the 500-hPa zonal-integrated meridional streamfunction $\left(10^{10} \mathrm{~kg} \mathrm{~s}^{-1}\right)$. Light/ dark shading marks the uncertainty (ensemble mean \pm 1 standard deviation) of the 23 CMIP3 GCMs in climatology/change under the A1B scenario.

In response to a uniform SST increase without any gradient, the Walker circulation weakens because of both the MASC and $\mathrm{LH}_{\text {SUSI }}^{*}$ effects in the western and eastern Pacific, respectively. The SST patterns in CM2.1 significantly reduce the Walker circulation in the western Pacific, but accelerate it in the eastern basin. Because the MASC effect is strong over a vast area of the equatorial Pacific, the Walker circulation slowdown is robust among the CMIP3 models under the A1B scenario.

In response to a uniform SST warming, the Hadley circulation slowdown is due to the MASC effect. In the A1B simulation with CM2.1, however, the slowdown is limited to the Northern Hemispheric cell while the Southern Hemispheric cell accelerates. Our LBM results show that this asymmetric response is due to SST patterns, specifically an interhemispheric asymmetry with greater SST warming in the Northern than the Southern Hemisphere. The Hadley circulation change varies among the CMIP3 models, and our results suggest that this intermodel uncertainty is due to the opposing effects of MASC-LH SUSI $^{*}$ and SST patterns in the Southern Hemisphere. The meridional variations of SST warming in CM2.1 are among the strongest of the CMIP3 models. In some coupled models with weak SST patterns-e.g., the Canadian Centre for Climate Modelling and Analysis (CCCma) Coupled GCM, version 3.1 (CGCM3.1) T63, the Goddard Institute for Space Studies Atmosphere-Ocean Model (GISS-AOM), the Model for Interdisciplinary Research on Climate 3.2, high-resolution version [MIROC3.2(hires)], and the Meteorological Research Institute Coupled General Circulation
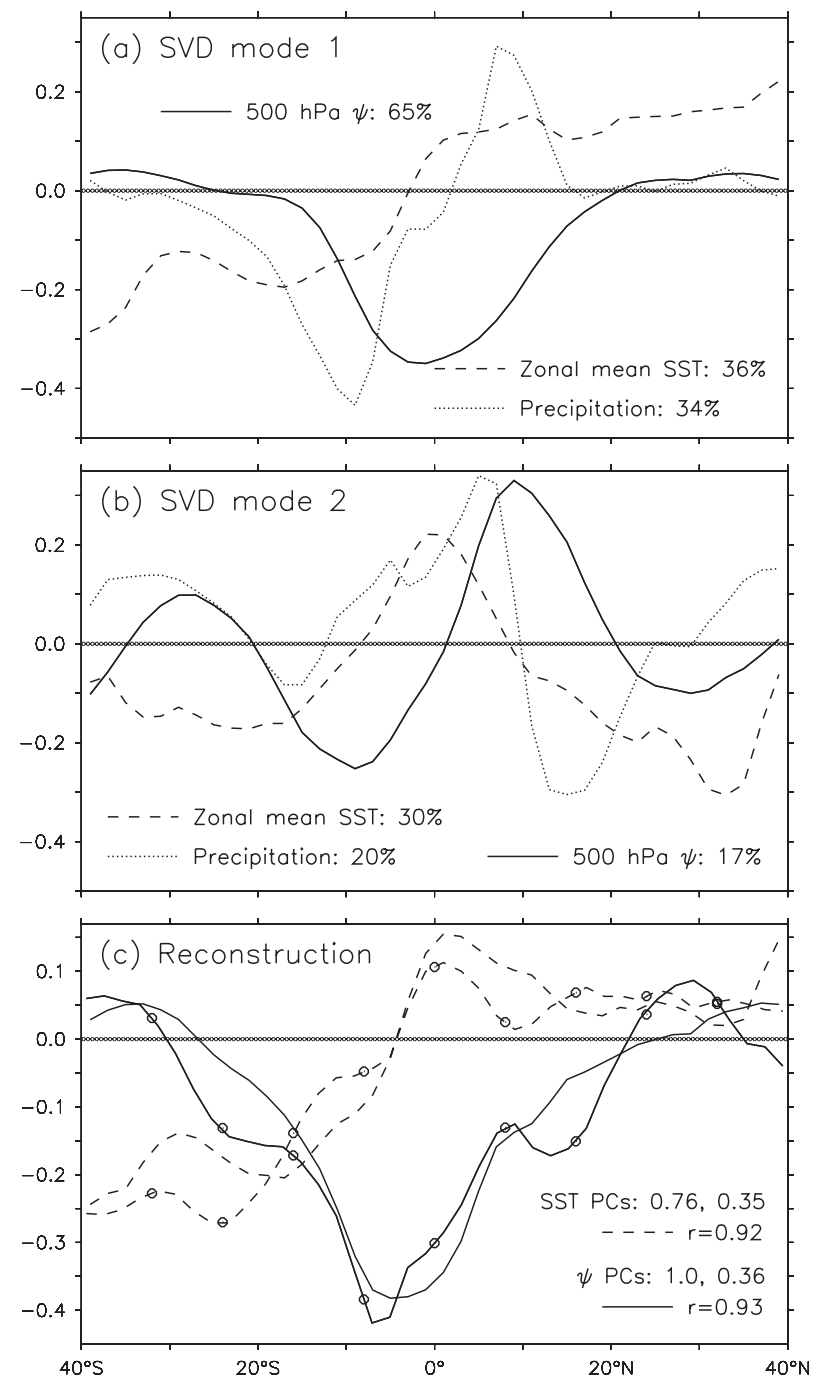

FIG. 9. (a),(b) First two modes of the intermodel SVD analyses between the twenty-first-century annual mean changes of zonal mean SST/precipitation and 500-hPa zonal-integrated meridional streamfunction $(\psi)$ among 23 CMIP3 GCMs under the A1B scenario. (c) Deviations (solid) of SST (K) and $\psi\left(2 \times 10^{10} \mathrm{~kg} \mathrm{~s}^{-1}\right)$ in $\mathrm{CM} 2.1$ from the CMIP3 ensemble means with their reconstructions (dashed) by using these two leading SVD modes. Also shown are the principle components (PCs; projections of the deviations to each mode) and latitudinal correlations ( $r$, between the deviations and reconstructions) for each variable.

Model, version 2.3.2a (MRI CGCM2.3) (not shown)the MASC effect to slow down the Hadley circulation in both hemispheres can be stronger than the SST pattern effect, resulting in a weakened Hadley circulation in both hemispheres (Fig. 8).

The present study focuses on annual mean results. The boreal summer simulations show similar skills to the annual mean ones in reproducing GCM results. For the boreal winter, LBM's simulation skills are much lower. This seasonality appears consistent with the theory of 
Schneider et al. (2010). An important parameter for this theory is the local Rossby number:

$$
\text { Ro }=-\zeta / f,
$$

where $\zeta$ is relative vorticity and $f$ is the Coriolis parameter. When Ro $\rightarrow 1$, the angular momentum conservation degenerates and provides no constraint on the mean meridional mass flux, and the tropical circulation change responds directly to the thermal driving. When Ro $\rightarrow 0$, circulation is dynamically constrained and the change in the eddy momentum flux divergence plays an important role. Figure 5 of Schneider et al. (2010) shows that only in boreal summer are the local Ro larger than 0.5 in much of the upper branch of the Hadley cell in both hemispheres, while in boreal winter, the local Ro is smallest. The eddy effects (Lu et al. 2007; Schneider et al. 2010) are not considered in this study but worth indepth investigations.

From the energetic point of view, the increased vertical gradients of potential temperature in global warming enhance the efficiency of the Hadley cell in transporting the dry static energy from the equator to the subtropics, assuming the strength of the Hadley cell does not change. This is equivalent to the MASC mechanism. Held and Soden (2006) show that the increase of moisture convergence (supplying the $\mathrm{LH}$ ) is insufficient to overcome the dry energy divergence. Therefore, more energy is transported poleward, flattening the tropical tropospheric meridional temperature gradients, reducing the tropical wind shear, pushing the synoptic eddies poleward and thus, expanding and weakening the Hadley circulation. During the warm phase of the ENSO, enhanced poleward energy transport is also found because of the wind change associated with enhanced SST gradient (Lu et al. 2008). In global warming, SST pattern effects on energy transport need further investigation, but SST gradient change is much weaker than global-mean warming. The MASC, instead of being caused by circulation change, drives the winds to respond differently from the ENSO with same sign of energy transport change.

Note: At the time of peer review, it came to our attention that Muller and O'Gorman (2011) have independently proposed a similar decomposition method. Their analysis with CMIP3 simulations supports our energetic view on the MASC effect. Our study goes beyond the diagnostic scheme and shows that LBM is useful in this framework to compute the dynamical component of dry energy divergence.

Acknowledgments. We wish to thank various modeling groups for providing their outputs, the Program for Climate Model Diagnostics and Intercomparison
(PCMDI) and the WCRP's Working Group on Coupled Modeling (WGCM) for collecting, archiving, and making the WCRP CMIP3 multimodel dataset readily available, and the Office of Science, U.S. Department of Energy for supporting this dataset. We thank the GFDL for providing the outputs of their ensemble integrations, and M. Watanabe for releasing the LBM codes. We wish to acknowledge use of the Ferret program for analysis and graphics. Comments from anonymous reviewers were helpful in improving the paper. B. Xiang and X. Zheng are appreciated for technical discussions. This work is supported by NSF, NOAA, NASA, and JAMSTEC.

\section{REFERENCES}

Alexander, M. A., I. Bladé, M. Newman, J. R. Lanzante, N. C. Lau, and J. D. Scott, 2002: The atmospheric bridge: The influence of ENSO teleconnections on air-sea interaction over the global oceans. J. Climate, 15, 2205-2231.

Betts, A. K., 1998: Climate-convection feedbacks: Some further issues. Climatic Change, 39, 35-38.

, and W. Ridgway, 1989: Climatic equilibrium of the atmospheric convective boundary layer over a tropical ocean. J. Atmos. Sci., 46, 2621-2641.

Bretherton, C., and A. Sobel, 2003: The Gill model and the weak temperature gradient approximation. J. Atmos. Sci., 60, 451-460.

Chou, C., and J. D. Neelin, 2004: Mechanisms of global warming impacts on regional tropical precipitation. J. Climate, 17, 2688-2701.

_ — C C.-A. Chen, and J.-Y. Tu, 2009: Evaluating the "richget-richer" mechanism in tropical precipitation change under global warming. J. Climate, 22, 1982-2005.

Delworth, T. L., and Coauthors, 2006: GFDL's CM2 global coupled climate models. Part I: Formulation and simulation characteristics. J. Climate, 19, 643-674.

de Szoeke, S. P., and S.-P. Xie, 2008: The tropical eastern Pacific seasonal cycle: Assessment of errors and mechanisms in IPCC AR4 coupled ocean-atmosphere general circulation models. J. Climate, 21, 2573-2590.

Frierson, D. M. W., J. Lu, and G. Chen, 2007: Width of the Hadley cell in simple and comprehensive general circulation models. Geophys. Res. Lett., 34, L18804, doi:10.1029/2007GL031115.

Fu, Q., C. M. Johanson, J. M. Wallace, and T. Reichler, 2006: Enhanced mid-latitude tropospheric warming in satellite measurements. Science, 312, 1179.

Gastineau, G., L. Li, and H. Le Treut, 2009: The Hadley and Walker circulation changes in global warming conditions described by idealized atmospheric simulations. J. Climate, 22, 3993-4013.

GFDL Global Atmospheric Model Development Team, 2004: The new GFDL global atmosphere and land model AM2/LM2: Evaluation with prescribed SST simulations. J. Climate, 17, 4641-4673.

Gill, A. E., 1980: Some simple solutions for heat-induced tropical circulation. Quart. J. Roy. Meteor. Soc., 106, 447-462.

Held, I. M., and B. J. Soden, 2006: Robust responses of the hydrological cycle to global warming. J. Climate, 19, 5686-5699.

$\mathrm{Hu}$, Y., and Q. Fu, 2007: Observed poleward expansion of the Hadley circulation since 1979. Atmos. Chem. Phys., 7, 52295236, doi:10.5194/acp-7-5229-2007. 
Johanson, C. M., and Q. Fu, 2009: Hadley cell widening: Model simulations versus observations. J. Climate, 22, 2713-2725.

Johnson, N. C., and S.-P. Xie, 2010: Changes in the sea surface temperature threshold for tropical convection. Nat. Geosci., 3, 842-845, doi:10.1038/ngeo1008.

Knutson, T. R., and S. Manabe, 1995: Time-mean response over the tropical Pacific to increased $\mathrm{CO}_{2}$ in a coupled ocean-atmosphere model. J. Climate, 8, 2181-2199.

— J. J. Sirutis, S. T. Garner, G. A. Vecchi, and I. M. Held, 2008: Simulated reduction in Atlantic hurricane frequency under twenty-first-century warming conditions. Nat. Geosci., 1, 359-364.

Lindzen, R. S., 1990: Some coolness concerning global warming. Bull. Amer. Meteor. Soc., 71, 288-299.

Liu, Z., S. Vavrus, F. He, N. Wen, and Y. Zhong, 2005: Rethinking tropical ocean response to global warming: The enhanced equatorial warming. J. Climate, 18, 4684-4700.

Lu, J., G. A. Vecchi, and T. Reichler, 2007: Expansion of the Hadley cell under global warming. Geophys. Res. Lett., 34, L06805, doi:10.1029/2006GL028443.

—, G. Chen, and D. M. W. Frierson, 2008: Response of the zonal mean atmospheric circulation to $\mathrm{El}$ Nino versus global warming. J. Climate, 21, 5835-5851.

Matsuno, T., 1966: Quasi-geostrophic motions in the equatorial area. J. Meteor. Soc. Japan, 44, 25-42.

Muller, C. J., and P. A. O'Gorman, 2011: An energetic perspective on the regional response of precipitation to climate change. Nat. Climate Change, 1, 266-271, doi:10.1038/nclimate1169.

Rodwell, M. J., and B. J. Hoskins, 1996: Monsoons and the dynamics of deserts. Quart. J. Roy. Meteor. Soc., 122, 1385-1404, doi:10.1002/qj.49712253408.

Schneider, T., P. A. O'Gorman, and X. J. Levine, 2010: Water vapor and the dynamics of climate changes. Rev. Geophys., $\mathbf{4 8 ,}$ RG3001, doi:10.1029/2009RG000302.
Tanaka, H. L., N. Ishizaki, and A. Kitoh, 2004: Trend and interannual variability of Walker, monsoon and Hadley circulations defined by velocity potential in the upper troposphere. Tellus, 56A, 250-269.

Vecchi, G. A., and B. J. Soden, 2007a: Global warming and the weakening of the tropical circulation. J. Climate, 20, 43164340 .

$\longrightarrow$, and - 2007b: Effect of remote sea surface temperature change on tropical cyclone potential intensity. Nature, 450, 1066-1070.

- , and — 2007c: Increased tropical Atlantic wind shear in model projections of global warming. Geophys. Res. Lett., 34, L08702, doi:10.1029/2006GL028905.

,,-- A. T. Wittenberg, I. M. Held, A. Leetmaa, and M. J. Harrison, 2006: Weakening of tropical Pacific atmospheric circulation due to anthropogenic forcing. Nature, 441, 73-76, doi:10.1038/nature04744.

— K. K. Swanson, and B. J. Soden, 2008: Whither hurricane activity? Science, 322, 687-689.

Watanabe, M., and M. Kimoto, 2000: Atmosphere-ocean thermal coupling in the North Atlantic: A positive feedback. Quart. J. Roy. Meteor. Soc., 126, 3343-3369; Corrigendum, 127, 733734.

— , and F.-F. Jin, 2004: Dynamical prototype of the Arctic Oscillation as revealed by a neutral singular vector. J. Climate, $\mathbf{1 7}$, 2119-2138.

Wentz, F. J., L. Ricciardulli, K. Hilburn, and C. Mears, 2007: How much more rain will global warming bring? Science, 317, 233-235.

Wittenberg, A. T., A. Rosati, N.-C. Lau, and J. J. Ploshay, 2006: GFDL's CM2 global coupled climate models. Part III: Tropical Pacific climate and ENSO. J. Climate, 19, 698-722.

Xie, S.-P., C. Deser, G. A. Vecchi, J. Ma, H. Teng, and A. T. Wittenberg, 2010: Global warming pattern formation: Sea surface temperature and rainfall. J. Climate, 23, 966-986. 